\title{
Strong Internal Waves Generated by the Interaction of the Kuroshio and Tides over a Shallow Ridge
}

\author{
EIJI MASUNAGA \\ Center for Water Environment Studies, Ibaraki University, Mito, Japan \\ YUSUKE UCHIYAMA \\ Department of Civil Engineering, Kobe University, Kobe, Japan \\ HIDEKATSU YAMAZAKI \\ Department of Ocean Sciences, Tokyo University of Marine Science and \\ Technology, Tokyo, Japan
}

(Manuscript received 20 November 2018, in final form 22 August 2019)

\begin{abstract}
The Kuroshio and tides significantly influence the oceanic environment off the Japanese mainland and promote mass/heat transport. However, the interaction between the Kuroshio and tides/internal waves has not been examined in previous works. To investigate this phenomenon, the two-dimensional high-resolution nonhydrostatic oceanic Stanford Unstructured Nonhydrostatic Terrain-Following Adaptive Navier-Stokes Simulator (SUNTANS) model was employed. The results show that strong internal tides propagating upstream in the Kuroshio are generated at a near-critical internal Froude number $\left(\mathrm{Fr}_{i}=0.91\right)$. The upstream internal wave energy flux reaches a magnitude of $12 \mathrm{~kW} \mathrm{~m}^{-1}$, which is approximately 3 times higher than that of internal waves without the Kuroshio. On the other hand, under supercritical conditions, the Kuroshio suppresses the internal wave energy flux. The interaction of internal tides and the Kuroshio also generates upstream propagating high-frequency internal waves and solitary wave packets. The high-frequency internal waves contribute to the increase in the total internal wave energy flux up to $40 \%$ at the near-critical $\mathrm{Fr}_{i}$ value. The results of this study suggest that the interaction of internal tides and the Kuroshio enhances the upstream propagating internal tides under the specified conditions $\left(\mathrm{Fr}_{i} \sim 1\right)$, which may lead to deep ocean mixing and transport at significant distances from the internal wave generation sites.
\end{abstract}

\section{Introduction}

Internal waves play major roles in the global ocean circulation and Earth's climate system (Munk and Wunsch 1998). Internal waves in the ocean are generated mainly by barotropic tides and winds. Tidal forcing is a major contributor to internal waves, and internal waves with tidal frequencies are called internal tides. The interaction of the tidal flow and shallow ridges/sills is one of the major factors contributing to internal tide generation (Alford et al. 2015; Da Silva et al. 2015; Masunaga et al. 2018). The energy of internal waves increases when the topographic slope angle matches the beam angle of internal waves known as the

Corresponding author: Eiji Masunaga, eiji.masunaga.office@ vc.ibaraki.ac.jp critical slope (Cacchione et al. 2002). Internal waves transport energy from generation sites and finally break, inducing turbulence and mixing. Shoreward propagating internal waves increase their nonlinearity and generate strong turbulent mixing on shallow slopes (Richards et al. 2013; Masunaga et al. 2015), occasionally causing sediment resuspension and mass transport (Masunaga et al. 2017a).

A shallow ridge located in Luzon Strait in the South China Sea is well known as one of the world's strongest internal tide generation sites (Alford et al. 2015). The intensified tidal flow in the shallow strait increases wave steepness, resulting in the release of internal solitary packets from the internal wave generation site (Zhang et al. 2011; Guo and Chen 2014). Such internal solitary waves are formed when the internal Froude number $\left(\mathrm{Fr}_{i}\right)$ exceeds a critical value of one (Zhang et al. 2011), 


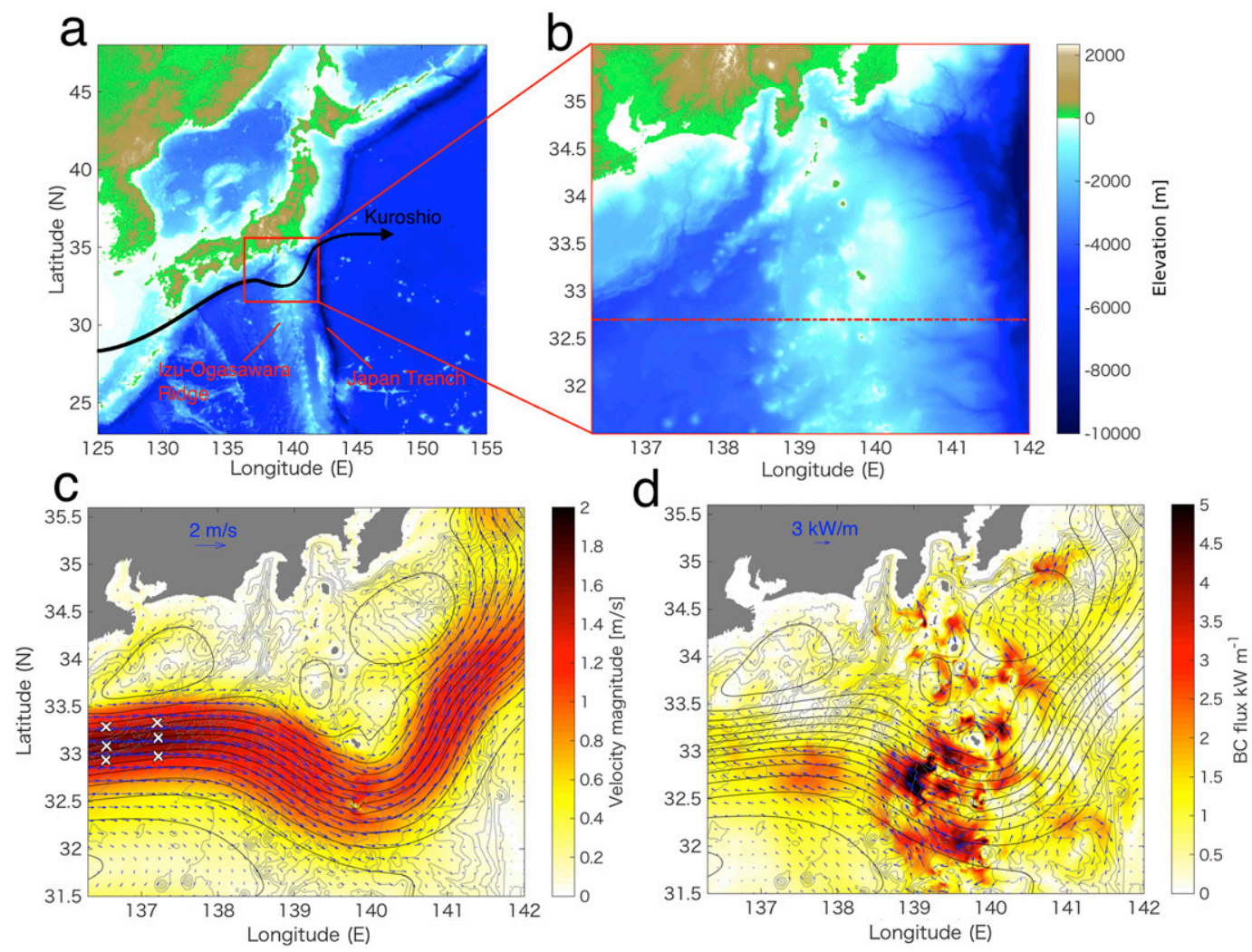

FIG. 1. (a),(b) Maps of the study area with bathymetry, (c) time-averaged surface velocity, and (d) time-averaged internal wave energy flux in August 2013 provided by Masunaga et al. (2018). The solid (gray) black contours in (b) and (c) denote the sea surface heights (isobaths) plotted at intervals of $0.1 \mathrm{~m}(500 \mathrm{~m})$. The red dash-dot line in (b) indicates the transect line used for the bathymetry studies.

where the internal Froude number is defined as the ratio between the current speed $u$ and the internal wave speed $c_{i}, \mathrm{Fr}_{i}=u / c_{i}$.

In addition to Luzon Strait, recent studies have found that energetic internal waves are generated at the Izu-Ogasawara Ridge stretching over $600 \mathrm{~km}$ off the Japanese mainland (Fig. 1a). Barotropic tides generate strong tidal flows across the ridge. The interaction between barotropic tidal currents and the ridge generates internal waves (Masunaga et al. 2017b, 2018). Masunaga et al. (2018) conducted numerical simulations considering all possible processes (three-dimensional flows, tides, winds, and heat, radiation, and freshwater water fluxes). They found that $92 \%$ of the total internal wave flux was caused by internal tides, which contributed to $10 \%$ of the total kinetic energy in the study area. Therefore, internal tides play a significant role in physical processes that occur in the Izu-Ogasawara Ridge region. The Kuroshio strongly influences various physical processes over the Izu-Ogasawara Ridge as well as tides and internal tides. It crosses the ridge from west to east, and its flow speed reaches a magnitude of $2.0 \mathrm{~m} \mathrm{~s}^{-1}$ along the main axis. The interaction of the Kuroshio and shallow ridges promotes turbulent mixing (Hasegawa et al. 2008; Nikurashin and Ferrari 2010; Nagai et al. 2017)

Physical processes associated with the Kuroshio and internal tides have been discussed in much detail but separately. The interaction between these two processes has not been systematically investigated yet. The recent high-resolution numerical simulations with a horizontal resolution of $1 \mathrm{~km}$ conducted by Masunaga et al. (2018) showed for the first time that the interaction of the Kuroshio with internal tides likely induced an upstream strong internal tide energy flux (westward) from the IzuOgasawara Ridge. Figure 1d shows the intensified upstream internal tide energy flux along the Kuroshio axis off the Izu-Ogasawara Ridge. The maximum value of the internal tide energy flux reaches $8.4 \mathrm{~kW} \mathrm{~m}^{-1}$ at the point of intersection between the Kuroshio and the ridge. The strong internal tide energy flux reaches an order of $10 \mathrm{~kW} \mathrm{~m}^{-1}$ in other ridges, such as Hawaiian Ridge (Rudnick et al. 2003) and ridges in Luzon Strait (Alford et al. 2015). Thus, the Izu-Ogasawara Ridge is one of the most energetic internal wave generation sites in the ocean. Masunaga et al. (2018) took into account all possible forcings (tides, the Kuroshio, winds, and heat, 


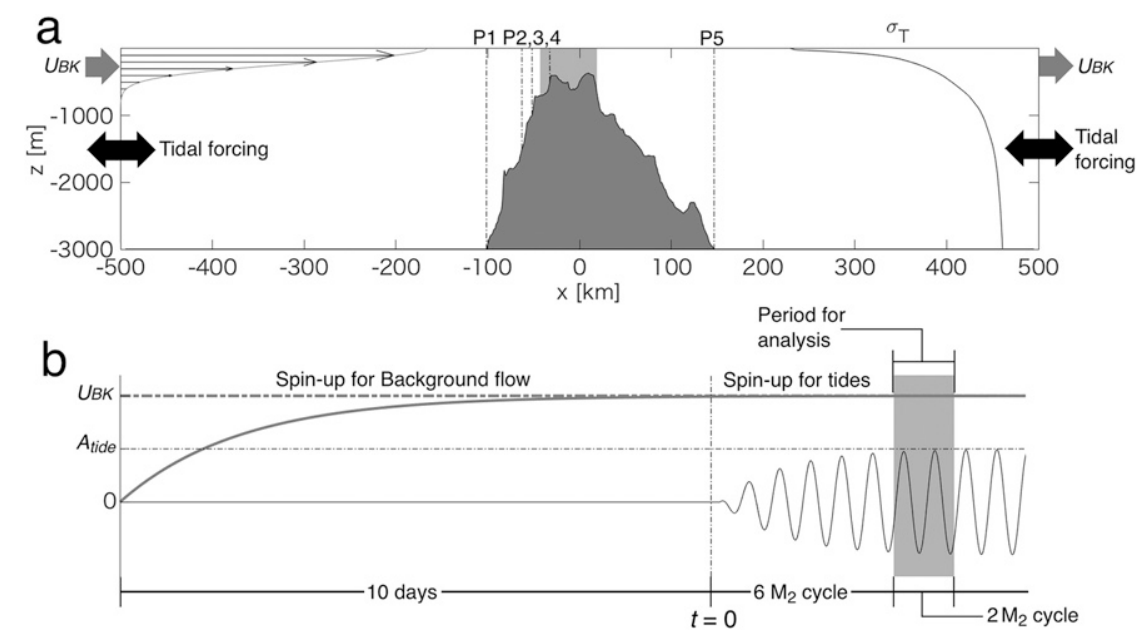

FIG. 2. (a) A schematic image of the model configuration with bathymetry and (b) time series of boundary forcing for the background flow (thick gray line) and barotropic tides (thin black line). Notations P1-5 in (a) show the data locations for Figs. 9 and 10. The light gray shaded area in (a) represents the region used for energy budget analysis.

radiation, and freshwater fluxes); however, it was difficult to extract the details of the interaction between the Kuroshio and tides due to the complexity of modeling numerous physical processes in realistic oceanic simulations. In contrast, Lamb and Dunphy (2018) conducted idealized two-dimensional (2D) $(x-z)$ numerical simulations of the internal waves generated over a sill with background shear flows and found that their interactions could enhance an asymmetrical internal wave structure on the upstream and downstream sides of the sill with enhanced upstream internal wave energy flux toward the upstream side. Although the authors found the existence of such interactions, their simplified model consisted of a small Gaussian-shape sill with a subcritical internal Froude number.

In this study, we conducted numerical simulations over realistic sill topography using two-dimensional nonlinear Stanford Unstructured Nonhydrostatic Terrain-Following Adaptive Navier-Stokes Simulator (SUNTANS) model (Fringer et al. 2006). We present the model configuration in section 2. Section 3 analyzes the physical processes and energetics related to the interaction of the Kuroshio with internal tides. Finally, section 4 states the results of our study and summarizes the major conclusions.

\section{Model configuration}

\section{a. Model setup}

Two-dimensional modeling has been frequently used to investigate internal wave dynamics (Bourgault et al. 2014; Arthur and Fringer 2016; Masunaga et al. 2017a) because this approach significantly reduces computational efforts and time. On the other hand, 2D models cannot reproduce many physical processes related to large-scale geostrophic motions. However, it allows us to significantly increase the grid resolution and thus more accurately characterize the broadband nature of internal waves as compared to the coarser resolution of three-dimensional (3D) models. To investigate relatively small-scale physical processes related to the interaction of the Kuroshio and internal tides, a 2D $(x-z)$ version of the SUNTANS model (Fringer et al. 2006) was used to solve the Reynolds-averaged nonhydrostatic Navier-Stokes equation with the Boussinesq approximation, depth-averaged continuity equation, free surface, and salinity and temperature transport equations. The water density is calculated from temperature, salinity, and pressure via an equation of the state (Millero and Poisson 1981). The Mellor-Yamada level 2.5 turbulent closure model is employed to compute the vertical eddy viscosity and diffusivity (Mellor and Yamada 1982). The horizontal eddy viscosity and eddy diffusivity are set to $1 \times 10^{-2} \mathrm{~m}^{2} \mathrm{~s}^{-1}$ and 0 , respectively. The quadratic bottom drag coefficient $C_{D}=0.0025$ is kept constant throughout the model domain. The time step is set to $10 \mathrm{~s}$ in order to maintain numerical stability. The horizontal grid spacing is set to $100 \mathrm{~m}$ in the middle of the domain covering the ridge region (Fig. 2a, $-250<x<250 \mathrm{~km}$ ); it is also stretched to $10 \mathrm{~km}$ at the western and eastern boundaries to avoid the reflection of high-frequency internal tides from the model boundaries. As a result, the model consists of 5098 horizontal cells containing 150 stretched vertical $z$ layers with grid height refinement near the sea surface. The minimum (surface) and maximum (bottom 


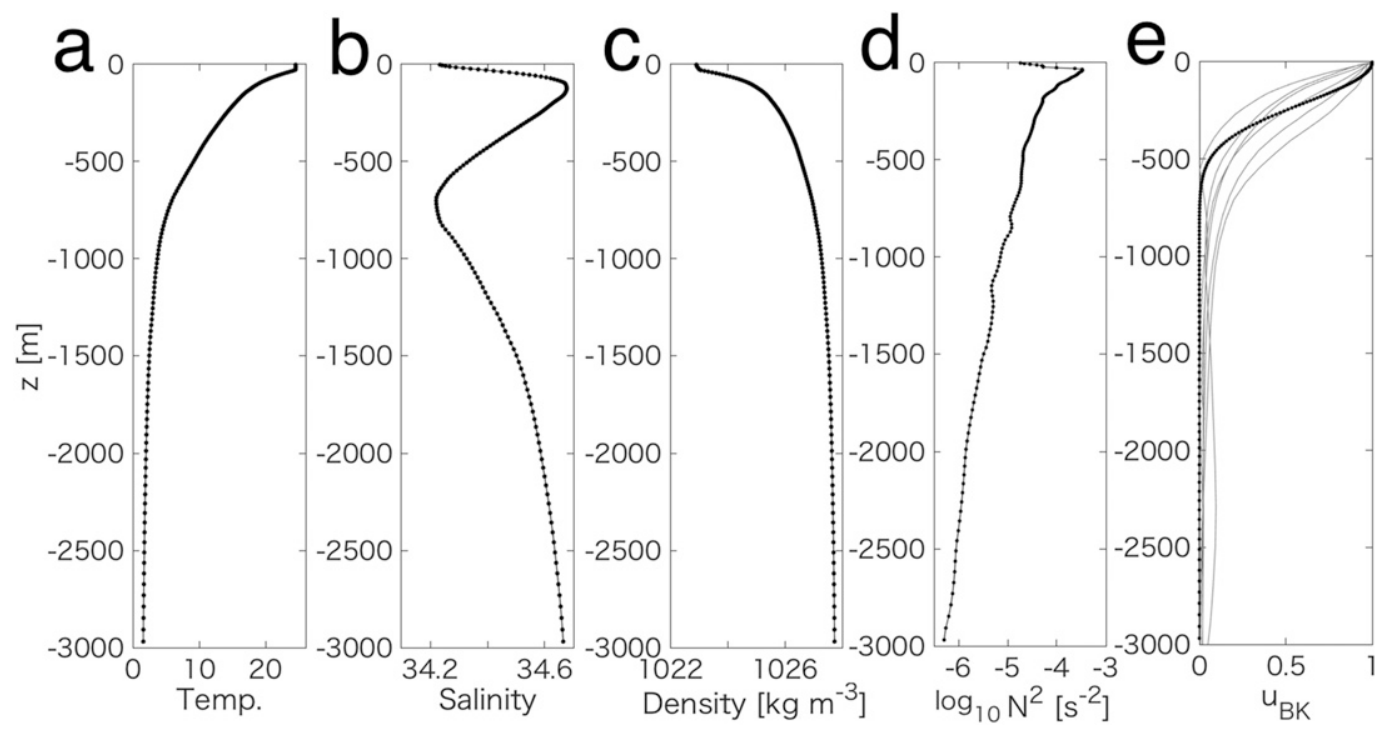

FIG. 3. Initial (a) temperature, (b) salinity, and (c) density, (d) $N^{2}$ profiles, and (e) normalized background flow at boundaries. The dots represent points on the $z$-level grid. Gray lines in (e) represent time-averaged current profiles taken at six locations in the upstream of the Kuroshio shown as white $\mathrm{X}$ marks in Fig. 1c.

at a depth of $3000 \mathrm{~m}$ ) vertical gridcell sizes are equal to 3.2 and $62.0 \mathrm{~m}$, respectively. Earth's rotation is ignored to simplify the model setup. Although the model is idealized by using the $2 \mathrm{D}$ domain without taking into account Earth's rotation, it is expected to reproduce the primary physical processes related to the Kuroshio and internal tides. Surface heat, freshwater fluxes, and wind forcing are not considered in this study since we focus on the interaction between the Kuroshio and internal waves with relatively short time scales.

\section{b. Bathymetry and initial conditions}

We selected the bathymetry along latitude $32.7^{\circ} \mathrm{N}$ (Figs. 1b and 2a), where the main Kuroshio axis flowed approximately across the Izu-Ogasawara Ridge in August 2013, (Masunaga et al. 2018). The bathymetry data were taken from the J-EGG500 dataset distributed by Japan Oceanographic Data Center. The maximum far-field depth from the ridge is set to $3000 \mathrm{~m}$ to simplify the model and avoid computational efforts of resolving the deep trench in the far field. According to literature, internal tide generation and dissipation occur in depths shallower than $3000 \mathrm{~m}$ in the study area (Masunaga et al. 2017b, 2018). Thus, the assumption of the maximum depth $(3000 \mathrm{~m})$ is a reasonable approximation to investigate internal tide dynamics. As shown in Fig. 2, the origin of the horizontal coordinate axis $(x)$ is located at the summit of the ridge, and the positive (negative) direction corresponds to the eastward (westward) direction.

To simulate internal tides in the summer season presented in Masunaga et al. (2018), the initial temperature and salinity vertical profiles are taken from the summer seasonal climatological database World Ocean Atlas 2009 (WOA09; National Oceanographic Data Center; longitude: $141.5^{\circ} \mathrm{E}$, latitude: $34.5^{\circ} \mathrm{N}$ ). The buoyancy frequency is defined as

$$
N=\sqrt{-\frac{g}{\rho_{0}} \frac{d \rho}{d z}},
$$

where $g$ is the gravitational acceleration, $\rho$ is the water density, and $\rho_{0}$ is the reference water density $\left(1024 \mathrm{~kg} \mathrm{~m}^{-3}\right)$. The squared buoyancy frequency $N^{2}$, shows the maximum vertical density gradient located at the depth of approximately $50 \mathrm{~m}$ (Fig. 3d). The horizontal distributions of the initial salinity and temperature are assumed to be uniform. It should be noted that the salinity minimum is observed in the subsurface layer at $z \sim-700 \mathrm{~m}$ due to the intrusion of the cold lowsalinity Oyashio water from the northern area of Japan. The initial velocity and free surface height are set to zero throughout the entire model domain.

\section{c. Boundary forcing}

The Kuroshio is generated by the effects of Earth's rotation and winds on the large/global oceanic scale. The proposed 2D model is not able to reproduce it spontaneously. Instead, a mean background flow is imposed to represent the Kuroshio in the 2D domain, whose eastern and western boundaries are forced by the prescribed idealized flow mimicking the Kuroshio as an exponential function with respect to depth as 


$$
u_{\mathrm{BK}}=U_{\mathrm{BK}} \exp \left(-\frac{z^{2}}{\sigma^{2}}\right),
$$

where $U_{\mathrm{BK}}$ is the maximum background velocity at the sea surface, $z$ is the vertical coordinate, and $\sigma(=300 \mathrm{~m})$ is the thickness of the Kuroshio. The western and eastern boundaries correspond to $x=-500$ and $500 \mathrm{~km}$, respectively. The background flow is imposed on the boundaries as a clamped boundary velocity forcing. The exponential velocity profile used in the model is compared with velocity profiles at six locations taken from the upstream of the Kuroshio presented in Masunaga et al. (2018) (Fig. 3e, the six locations are shown in Fig. $1 \mathrm{c}$ as white $\mathrm{X}$ marks). Although the velocities obtained by Masunaga et al. (2018) vary with space and depth, the simplified exponential velocity appears to be a reasonable approximation to reproduce the Kuroshio in the model. To reduce the degree of numerical instability and unrealistic oscillations at the beginning of simulations, the boundary background velocities are gradually increased with time as

$$
u_{\mathrm{BK}_{\mathrm{actual}}}=u_{\mathrm{BK}}\left[1-\exp \left(-t / \tau_{\mathrm{BK}}\right)\right],
$$

where $t$ is the time and $\tau_{\mathrm{BK}}$ is the spinup time scale set to 2 days. To generate barotropic tidal waves propagating from east to west, the eastern and western model boundaries are also forced by the barotropic tidal flows defined as

$$
u_{\text {Btide }}=A \sin (k x-\omega t),
$$

where $A$ is the barotropic velocity magnitude, $k$ is the horizontal wavenumber, $x$ is the horizontal distance coordinate, and $\omega$ is the tidal frequency. The amplitude and phase from a global tidal model were not employed in this study because of the idealized model domain in 2D. In this study, the parameters for Eq. (4) are chosen to reproduce the sea surface tidal oscillations with the $\mathrm{M}_{2}$ tidal frequency and amplitude of $0.5 \mathrm{~m}$ over the ridge. To meet this condition, the barotropic velocity amplitude $A$ and tidal frequency $\omega$ are set to $2.8 \times 10^{-2} \mathrm{~m} \mathrm{~s}^{-1}$ and $1.4 \times 10^{-4} \mathrm{rad} \mathrm{s}^{-1}$, respectively. The horizontal wavenumber $k$ is set to $8.2 \times 10^{-7} \mathrm{rad} \mathrm{m}^{-1}$ determined from the tidal frequency and linear longwave speed at a total depth of $3000 \mathrm{~m}\left(171.5 \mathrm{~m} \mathrm{~s}^{-1}\right)$, which can induce realistic barotropic tidal waves in the study area (Masunaga et al. 2017b). Tidal forcing is also gradually increased with time similarly to the background flow forcing in Eq. (3); however, in this case, the spinup time scale is set to 1 day.

The model was spun up for 10 days with the background flow; then, tidal forcing was added. The tidal
TABLE 1. Boundary conditions, internal Froude numbers, and

\begin{tabular}{|c|c|c|c|c|c|}
\hline & $U_{\mathrm{BK}}\left(\mathrm{m} \mathrm{s}^{-1}\right)$ & $a(\mathrm{~m})$ & $c_{i}\left(\mathrm{~m} \mathrm{~s}^{-1}\right)$ & $\mathrm{Fr}_{i}$ & $\mathrm{Ri}$ \\
\hline Run1 & 0 & 0.5 & 1.09 & 0 & - \\
\hline Run2 (Run2 $\left.2_{\text {w/oTide }}\right)$ & 0.25 & $0.5(0)$ & 1.09 & 0.23 & 85.7 \\
\hline Run3 (Run3 $\left.3_{\text {w/oTide }}\right)$ & 0.5 & $0.5(0)$ & 1.09 & 0.46 & 21.4 \\
\hline Run4 $\left(\right.$ Run $\left._{\text {w/oTide }}\right)$ & 0.75 & $0.5(0)$ & 1.09 & 0.68 & 9.5 \\
\hline Run5 (Run5 $\left.5_{\text {w/oTide }}\right)$ & 1 & $0.5(0)$ & 1.09 & 0.91 & 5.4 \\
\hline Run6 (Run6 w/oTide $)$ & 1.25 & $0.5(0)$ & 1.09 & 1.14 & 3.4 \\
\hline Run7 (Run7 $\left.7_{\text {w/oTide }}\right)$ & 1.5 & $0.5(0)$ & 1.09 & 1.36 & 2.4 \\
\hline
\end{tabular}
minimum Richardson numbers used for various model runs in this study.

spinup phase includes six $\mathrm{M}_{2}$ cycles $(74.52 \mathrm{~h}$ ), and the total spinup period is equal to approximately 13 days (Fig. 2b). We used the computational results of two $\mathrm{M}_{2}$ cycles $(24.48 \mathrm{~h})$ after the spinup for the data analysis in this study. The condition $t=0$ represents the moment when tidal forcing was imposed after the 10-day background flow spinup. Seven conditions for $U_{\mathrm{BK}}$ ranging from 0 to $1.5 \mathrm{~m} \mathrm{~s}^{-1}$ were conducted (Table 1 ). In addition to these runs involving tidal forcing, runs without tidal forcing were also conducted (Run2 $2_{\text {w/oTide }}-$ Run $_{\mathrm{w} / \mathrm{oTide}}$ ). The internal Froude number $\left(\mathrm{Fr}_{i}\right)=U_{\mathrm{BK}} / c_{i}, U_{\mathrm{BK}}$, tidal amplitude $(a)$, and minimum gradient Richardson number ( $\mathrm{Ri}$ ) determined at the model boundaries for all cases are presented in Table $1 . \mathrm{Fr}_{i}$ is computed from the ratio between $U_{\mathrm{BK}}$ and the linear mode-one internal wave speed $c_{i}$ at the top of the ridge $\left(c_{i}=1.09 \mathrm{~m} \mathrm{~s}^{-1}\right)$. Its magnitude ranges from 0 to $1.36 \mathrm{~m} \mathrm{~s}^{-1}$. The background current was not taken into the computation of $c_{i}$; thus, $c_{i}$ is determined from the background stratification and depths of the ridge. Note that $\mathrm{Fr}_{i}$ defined in this study is the maximum internal $\mathrm{Fr}_{i}$ at the shallowest summit on the ridge. The internal wave speed increases as the depth increases, so that $\mathrm{Fr}_{i}$ decreases away from the summit. The phase speed of the mode-one internal waves at the depth of $3000 \mathrm{~m}$ is $2.57 \mathrm{~m} \mathrm{~s}^{-1}$, namely, $\mathrm{Fr}_{i}$ is less than one in deep regions for super critical cases (Run6 and Run7). Therefore, internal waves cannot cross the ridge from the east to the west for super critical cases, but they can propagate westward in deep regions far away from the shallow summit. The Ri value is calculated from the vertical density gradient and buoyancy frequency as follows

$$
\mathrm{Ri}=N^{2} /(d u / d z)^{2} .
$$

The condition of $\mathrm{Ri}<1 / 4$ is necessary for instability, in which background flow is not linearly stable. The minimum $\mathrm{Ri}$ value is higher than $1 / 4$ for all cases; hence, the background flow does not cause instability at the model boundaries. 


\section{Results and discussion}

In the beginning of this section, we present the model results of the Kuroshio-internal tide interaction for four different cases: Run1 (a no-current case, $\mathrm{Fr}_{i}=0$ ), Run5 (a near-critical case, $\mathrm{Fr}_{i}=0.91$ ), Run7 (a supercritical case, $\mathrm{Fr}_{i}=1.36$ ), and $\mathrm{Run} 5_{\mathrm{w} / \mathrm{oTide}}$ (a case without tidal forcing). Afterward, we discuss the energy budgets of internal tides, high-frequency internal waves, and mixing due to internal tides.

\section{a. No-current case $\left(\mathrm{Fr}_{i}=0\right)$}

The case without the background Kuroshio flow (Run1) shows internal tide generation over the ridge and off-ridge radiation of internal tides. The dash-dot lines in Figs. $4 b$ and $4 c$ indicate the internal wave ray paths (characteristic slopes) calculated via the following dispersion relation

$$
s=\frac{k}{m}=\sqrt{\frac{\omega^{2}}{N^{2}-\omega^{2}}},
$$

where $s$ is the angle of the internal wave ray path, $k$ is the horizontal wavenumber, $m$ is the vertical wavenumber, and $\omega$ is the $\mathrm{M}_{2}$ tidal frequency. The horizontal velocity patterns shown in Fig. 4c follow the internal tide ray paths. The maximum internal Froude number computed from the tidal flow and internal wave speed is equal to 0.22 (below the critical value of one), which indicates that internal hydraulic jumps do not occur.

To estimate the intensity of internal tides, the depthintegrated internal wave energy flux is estimated via the following formula (Kang and Fringer 2012; Masunaga et al. 2017b):

$$
F_{\mathrm{IW}}=\int_{-d}^{\eta} p^{\prime} u_{\mathrm{BC}} d z
$$

where $d$ is the depth, $\eta$ is the sea surface elevation, $p^{\prime}$ is the high-frequency perturbation pressure excluding the pressure due to the free surface $\left(p^{\prime}=p-p_{0}\right.$, where $p_{0}$ is the low-frequency pressure component with a cutoff frequency of $3.9 \times 10^{-6} \mathrm{~s}^{-1}$ corresponding to a 3-day cycle), and $u_{\mathrm{BC}}$ is the lateral baroclinic (BC) velocity ( $u_{\mathrm{BC}}=u-u_{\mathrm{BT}}$, where $u_{\mathrm{BT}}$ is the barotropic velocity). The pressure $p$ contains both the hydrostatic and nonhydrostatic components. The barotropic velocity is defined as

$$
u_{\mathrm{BT}}=\frac{1}{\eta+d} \int_{-d}^{\eta} u d z
$$

The internal wave energy flux is computed in a fixed Eulerian frame. The maximum tidal excursion length
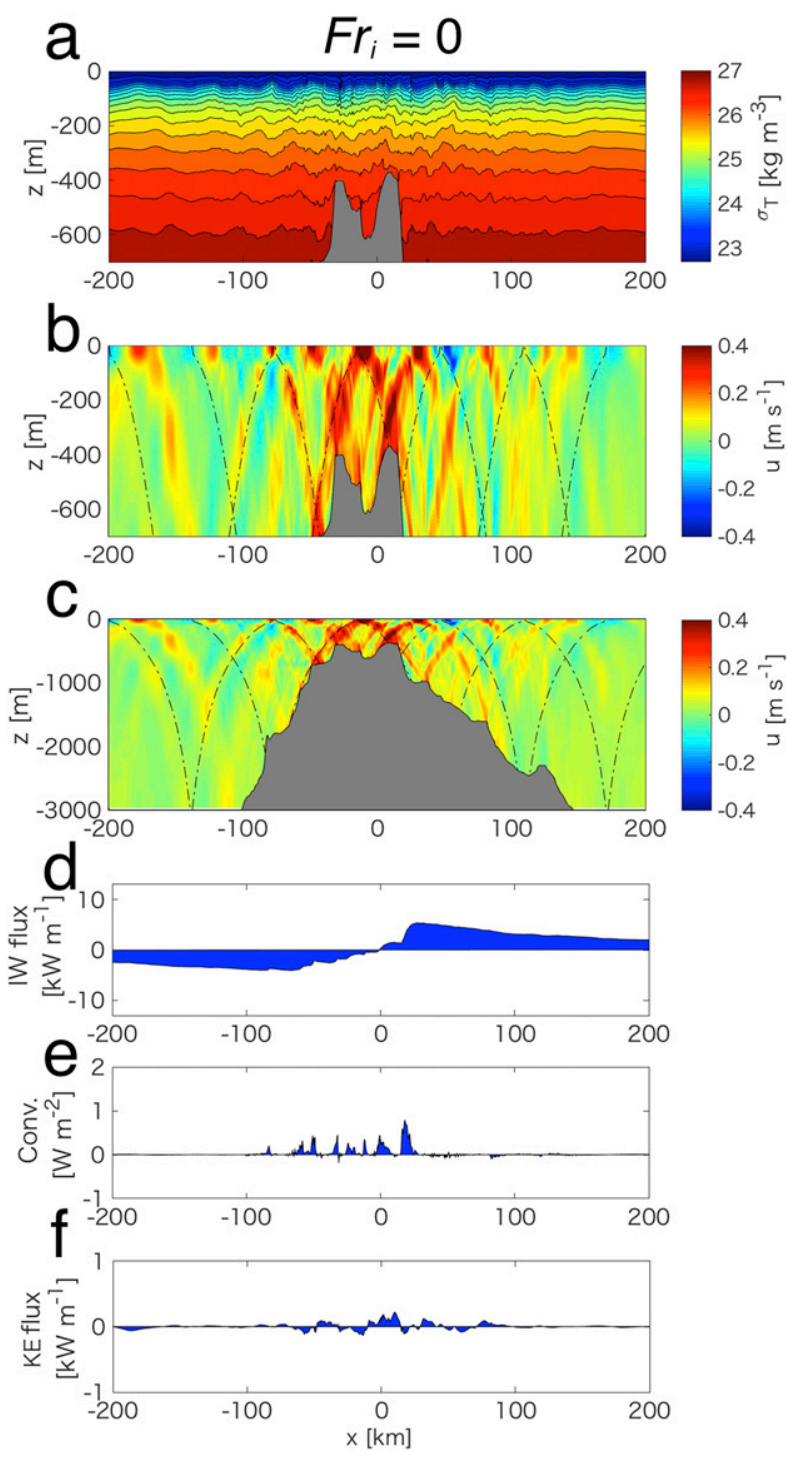

FIG. 4. Simulation results for Fr $=0$ (Run1). (a) Density, (b), (c) horizontal velocity at $t=84 \mathrm{~h}\left(t / T_{0}=6.76\right)$, (d) internal wave energy flux, (e) BT-BC conversion rate, and (f) BC kinetic energy flux. Panel (b) is an expanded version of (c). The dash-dot black lines in (b) and (c) denote the beams of internal waves with frequency $\mathrm{M}_{2}$.

over the shallow ridge is approximately $1700 \mathrm{~m}$ and is much smaller than the scale of the ridge. Figure $4 \mathrm{~d}$ shows the time-averaged depth-integrated internal wave energy flux averaged over two $\mathrm{M}_{2}$ cycles after the spinup. The internal wave energy flux was compared over several different time scales for time-averaging operations (two, three, and four $\mathrm{M}_{2}$ cycles) to evaluate significance of low-frequency biases. Because low-frequency biases were found to be much smaller than that of internal wave energy flux, we assume that the time average of the two $\mathrm{M}_{2}$ cycles is adequate in this context (see the appendix). 
The intensities of its eastward and westward components are distributed almost symmetrically and decrease with distance from the ridge; however, the magnitude of the eastward flux is slightly higher than that of the westward flux (their maximum intensities are equal to 5.4 and $4.1 \mathrm{~kW} \mathrm{~m}^{-1}$, respectively). This difference can only be due to the asymmetric shape of the topography. The intensity of internal wave generation can be estimated from the barotropic-baroclinic (BT-BC) conversion rate. The vertically integrated $\mathrm{BT}-\mathrm{BC}$ conversion rate $C$ is defined as (Kang and Fringer 2012)

$$
C=\int_{-d}^{\eta} \rho^{\prime} g W d z
$$

where $W$ is the barotropic vertical velocity represented as

$$
W=-\nabla \cdot\left[(d+z) u_{\mathrm{BT}}\right] .
$$

Figure $4 \mathrm{e}$ shows the time-averaged depth-integrated BT-BC conversion rate averaged over two $\mathrm{M}_{2}$ cycles. The conversion rate is significant mostly in the shallow area at depths of less than $1000 \mathrm{~m}$ with a maximum of around $0.8 \mathrm{~W} \mathrm{~m}^{-2}$ at $x \sim 18 \mathrm{~km}$ (Fig. 4e). The magnitudes of the internal wave flux and BT-BC conversion rate are consistent with the results of previous $3 \mathrm{D}$ numerical simulations that did not consider the direct influences of the Kuroshio (Masunaga et al. 2017b, 2018).

\section{b. Near-critical case $\left(\mathrm{Fr}_{i}=0.91\right)$}

Figure 5 displays the results of Run5 which includes the background Kuroshio flow at $\mathrm{Fr}_{i}=0.91$. It shows a significantly different internal wave distribution as compared to that for the case without the background flow (Run1). In particular, it contains sharp small-scale internal solitary wave-like vertical isopycnal displacements on the west side of the ridge (Fig. 5a), which are not observed on the east side. The velocity distribution consists of a horizontally compressed structure in the upper layer $(z>-1000 \mathrm{~m})$ on the west side (Figs. 5b,c). At the same time, the velocity distribution on the east side is horizontally stretched by the Kuroshio to produce a "fan-like" shape (Lamb and Dunphy 2018). These data for both the west and east sides are consistent with the results of numerical simulations conducted at subcritical Froude numbers by Lamb and Dunphy (2018).

The internal wave energy flux and BT-BC conversion rate for the cases that include a background current can be also estimated using Eqs. (7) and (8). However, the low-frequency background currents or oscillations have to be removed to compute these variables associated with the tidal oscillation, because the background flow
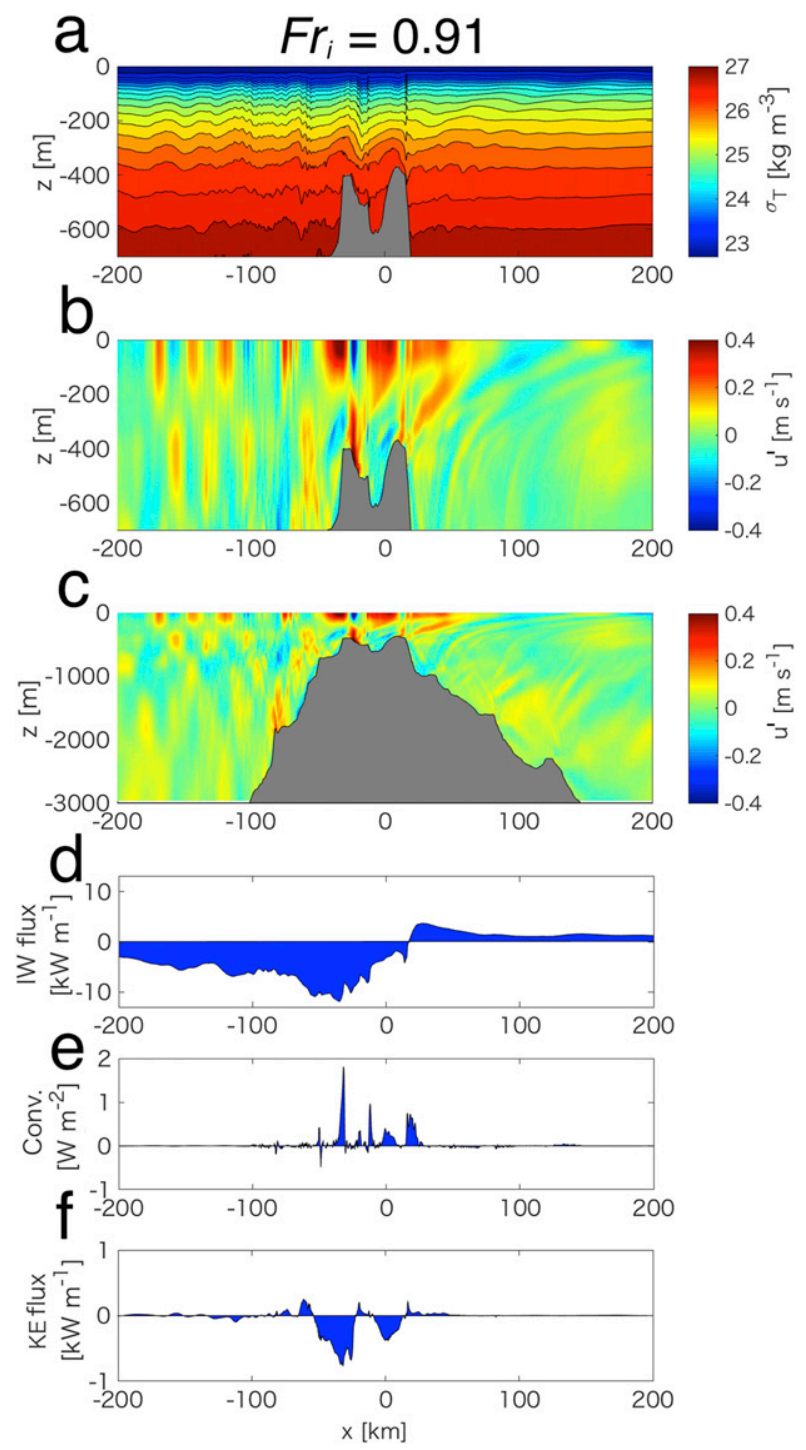

FIG. 5. Simulation results for Fr $=0.91$ (Run5). The horizontal velocity in (b) and (c) represents the perturbation component $u^{\prime}$.

also includes the vertically sheared BC component. The high-frequency (perturbation) components $u^{\prime}$ and $W^{\prime}$ are used in computations of the internal wave energy flux and BT-BC conversion. High-frequency velocities are extracted at a cutoff frequency of $3.9 \times 10^{-6} \mathrm{~s}^{-1}$ (period of 3 days). The internal wave energy flux for Run5 exhibits an asymmetric structure on the west and east sides of the ridge (Fig. 5d). Further, the westward flux is strongly enhanced, and its maximum amplitude reaches a value of $12.0 \mathrm{~kW} \mathrm{~m}^{-1}$, which is approximately 3 times higher than the magnitude for the case without the Kuroshio (Run1). The maximum westward flux matches a steep peak of the BT-BC conversion rate with an intensity of up to $1.8 \mathrm{~kW} \mathrm{~m}^{-2}$ at $x \sim-32 \mathrm{~km}$ (Fig. 5e). The maximum intensity of the internal wave energy flux 
and $\mathrm{BT}-\mathrm{BC}$ conversion is comparable to that by the Hawaiian Ridge where strong internal tides were observed (Merrifield and Holloway 2002). On the other hand, the eastward flux is smaller than the value for Run1 (its maximum amounts to $3.7 \mathrm{~kW} \mathrm{~m}^{-1}$, which is only $69 \%$ of the magnitude obtained from Run1).

Consequently, the background Kuroshio flow enhances the BT-BC conversion and the upstream propagation of internal tides and reduces the downstream internal tides, which is consistent with the findings of the recent study conducted by Lamb and Dunphy (2018). Such wave energy enhancement caused by the interaction of the background currents with upstream waves has been considered in studying the dynamics of surface gravity waves (Mei 1992). The numerical results obtained in this work suggest that the interaction of the Kuroshio and internal tides has a significant effect on the upstream internal wave flux, which is similar to that produced by the current-surface wave interaction.

\section{c. Supercritical case $\left(\mathrm{Fr}_{i}=1.36\right)$}

The numerical simulations conducted for the supercritical case (Run7, Fig. 6) produce water density and current structures similar to those for the near-critical case on the east side (Run5, Fig. 5). Meanwhile, the corresponding magnitude of horizontal velocity and westward internal wave energy flux are noticeably lower on the west side (see Figs. 5b,d and 6b,d). The maximum amplitude of the westward internal wave energy flux is $5.9 \mathrm{~kW} \mathrm{~m}^{-1}$, which is roughly half of the magnitude for the near-critical case. This low upstream internal wave flux results from the fact that the surface velocity exceeds the internal wave phase speed over the top of the ridge, suggesting that the Kuroshio flushes out internal wave energy generated around the top of the ridge downstream. The maximum eastward flux is $3.9 \mathrm{~kW} \mathrm{~m}^{-1}$, which is close to the value for the near-critical case. Although the internal wave radiation from the ridge is relatively low, the BT-BC conversion rate is apparently close to that of the near-critical case (Figs. 5e and 6e), indicating that a large amount of converted internal wave energy is dissipated over the ridge due to the Kuroshio (the details of this process are discussed in section $3 \mathrm{e}$ ).

\section{d. Case without tidal forcing}

The cases without tidal forcing are also considered to investigate the effects exclusively caused by the Kuroshio. Figure 7 shows the results of numerical simulations for Run5 $5_{\mathrm{w} / \mathrm{oTide}}\left(U_{\mathrm{BK}}=1, a=0\right)$. Here, the maximum lateral velocity at the side boundaries is $1.0 \mathrm{~m} \mathrm{~s}^{-1}$. The surface current speed is enhanced by the shallow ridge reaching a magnitude of $1.25 \mathrm{~m} \mathrm{~s}^{-1}$, and the maximum Froude number over the ridge exceeds
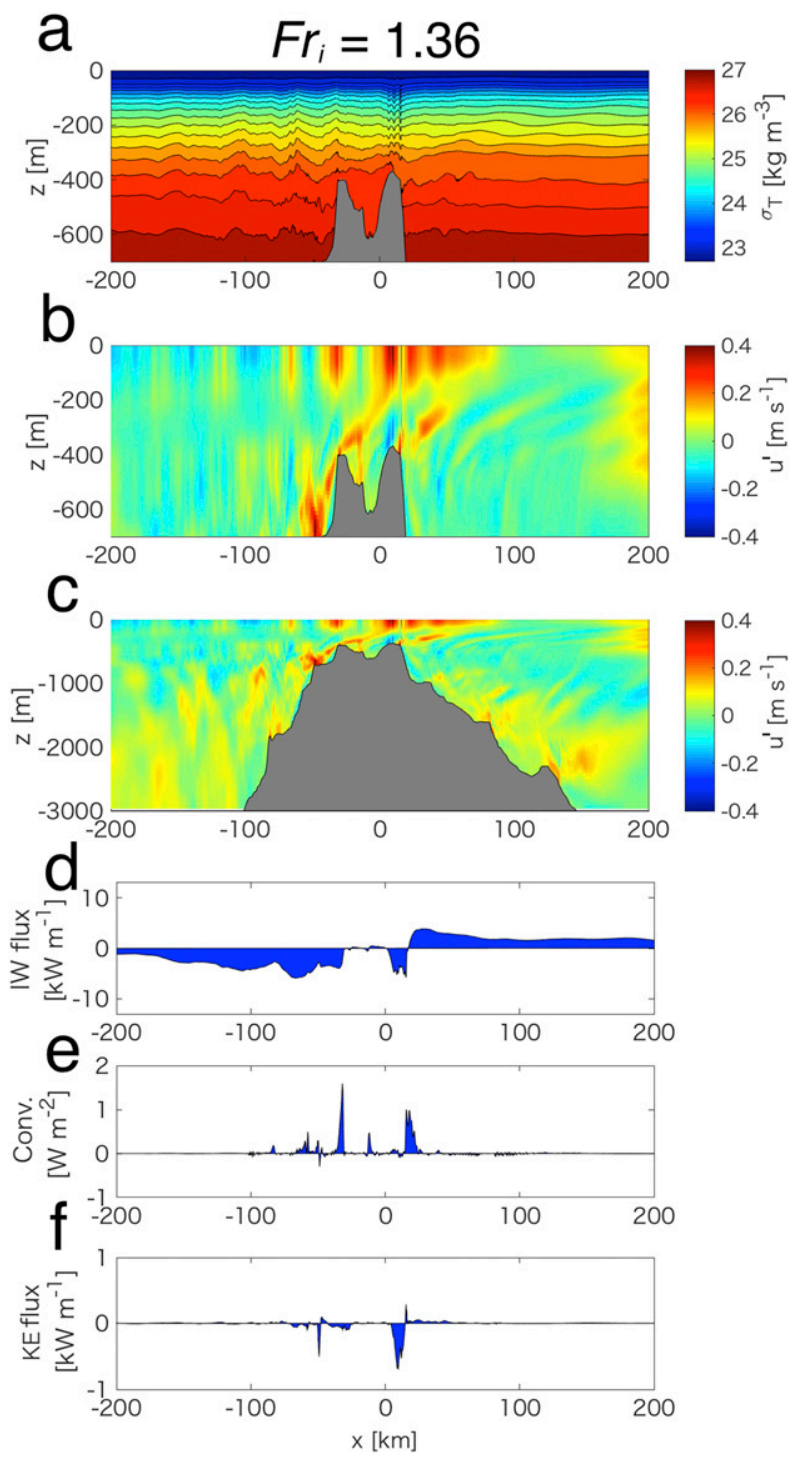

FIG. 6. Simulation results for $\mathrm{Fr}=1.36$ (Run7). The horizontal velocity in (b) and (c) represents the perturbation component $u^{\prime}$.

unity. A hydraulic jump is observed over the ridge, resulting in abrupt isopycnal displacements and velocity perturbations near the two shallow peaks of the sill (Fig. 7, $x=\sim-20$ and $10 \mathrm{~km}$ ). The internal wave intensity is much weaker than the values for the cases that take into account tidal forcing. The internal wave energy flux and BT-BC conversion are less than $0.1 \mathrm{~kW} \mathrm{~m}^{-1}$ and $2 \times 10^{-3} \mathrm{~W} \mathrm{~m}^{-2}$, respectively (Figs. 7f,g), which are three orders of magnitude smaller than the values computed for runs which include tidal forcing (Run5).

\section{e. Energy budget}

Several previous studies have reported that most of the total BC energy flux can be explained by the internal 

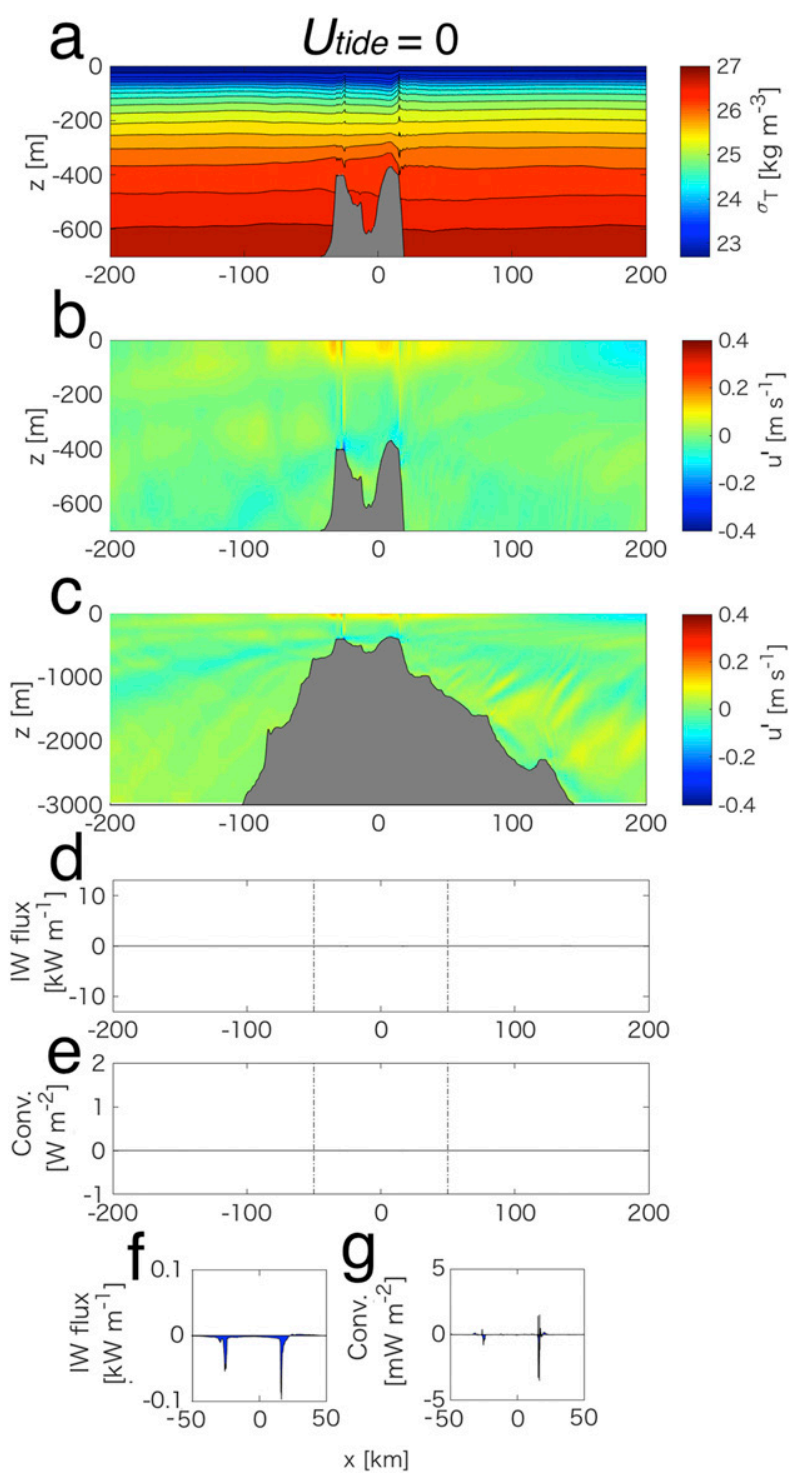

FIG. 7. Simulation results for the case without tidal forcing (Run5 $5_{\text {w/oTide }}$ ). The contents of (f) and (g) are identical to those of (d) and (e), respectively, but their vertical ranges are different. The horizontal velocity in (b) and (c) represents the perturbation component $u^{\prime}$.

wave energy flux (pressure work) $F_{\mathrm{IW}}$ (Venayagamoorthy and Fringer 2006; Kang and Fringer 2012), but strictly speaking the total $\mathrm{BC}$ energy flux is the sum of advection (kinetic energy and available potential energy), pressure (internal wave) and diffusion terms. By contrast to these studies, a recent work done by Lamb and Dunphy (2018) showed that the kinetic energy (KE) advection term also contribute to the total energy flux when internal waves interact with background flows. Thus, we assume that the total $\mathrm{BC}$ energy flux $F_{\mathrm{BC}}$ is the sum of the internal wave energy flux $F_{\mathrm{IW}}$ and the BC KE advection term $F_{\text {KEBC }}$ as follows

$$
F_{\mathrm{BC}}=F_{\mathrm{IW}}+F_{\mathrm{KEBC}} .
$$

The BC KE flux is given by (Kang and Fringer 2012)

$$
\begin{aligned}
F_{\mathrm{KEBC}} & =\int_{-d}^{\eta} u_{\mathrm{BC}} E_{\mathrm{KBC}} d z+\int_{-d}^{\eta} u_{\mathrm{BC}} E_{\mathrm{KBTBC}} d z, \\
E_{\mathrm{KBC}} & =\frac{1}{2} \rho\left(u_{\mathrm{BC}}^{2}+w^{2}\right), \text { and } \\
E_{\mathrm{KBTBC}} & =\rho u_{\mathrm{BT}} u_{\mathrm{BC}},
\end{aligned}
$$

where $w$ is the vertical velocity, and $E_{\mathrm{KBC}}$ and $E_{\mathrm{KBTBC}}$ are known as the $\mathrm{BC}$ kinetic energy and cross-term kinetic energy, respectively. To extract high (tidal) frequency motions from modeled data, the perturbation component of the velocity $u^{\prime}$ and density $\rho^{\prime}$ is used to compute $F_{\text {KEBC }}$ with a cutoff frequency of $3.9 \times 10^{-6} \mathrm{~s}^{-1}$ (the same approach as the computation of $F_{\mathrm{IW}}$ ). The time-averaged $F_{\text {KEBC }}$ for Run1, Run5, and Run7 are plotted in Figs. 4f, 5f, and 6f, respectively. For Run1, the magnitude $F_{\mathrm{KEBC}}$ is less than $0.2 \mathrm{~kW} \mathrm{~m}^{-1}$ and the direction of $F_{\mathrm{KEBC}}$ is not consistent with $F_{\mathrm{IW}}$. The interaction of the background flows and tides intensifies $F_{\text {KEBC }}$ over the shallow summits, reaching -0.8 and $-0.7 \mathrm{~kW} \mathrm{~m}^{-1}$ for Run5 and Run7, respectively (Figs. $5 \mathrm{f}$ and 6f). However, most of the generated $\mathrm{BC}$ kinetic energy decays over the shallow ridge. Overall, the magnitude of $F_{\text {KEBC }}$ is an order of $0.1-1 \mathrm{~kW} \mathrm{~m}^{-1}$, which is roughly 10 times smaller than that of $F_{\text {IW }}$ (Figs. 5d,f).

To investigate the internal tidal energetics in more detail, the time-averaged and area-depth-integrated energy terms, BT-BC conversion rate, $\mathrm{BC}$ radiation, and $\mathrm{BC}$ dissipation are calculated over the ridge for Run1-Run7. The analyzed area over the ridge is defined as the shallow part with depths of less than $700 \mathrm{~m}$ (depicted as the light gray shaded area in Fig. 2a). The $\mathrm{BT}-\mathrm{BC}$ conversion within the analyzed area explains $89 \%$ of the total BT-BC conversion in the whole model domain for Run5, thus, we assume that the analyzed area is suitable for the energy budget analysis. The BC radiation corresponds to the outgoing total $\mathrm{BC}$ energy flux from the analyzed area. The schematic of the energy budget analysis is shown in Fig. 8a. The BC dissipation is defined as

$$
\varepsilon_{\mathrm{BC}}=\nabla_{H} \cdot \overline{F_{\mathrm{BC}}}-\bar{C},
$$

where $\nabla_{H}$ is the horizontal gradient operator, and the overbar denotes the time averaging operation. The width of the $2 \mathrm{D}$ domain (in the $y$ direction) is assumed to be $1 \mathrm{~m}$ to compute area-integrated values. The time averaging period includes two $\mathrm{M}_{2}$ cycles after the spinup. 


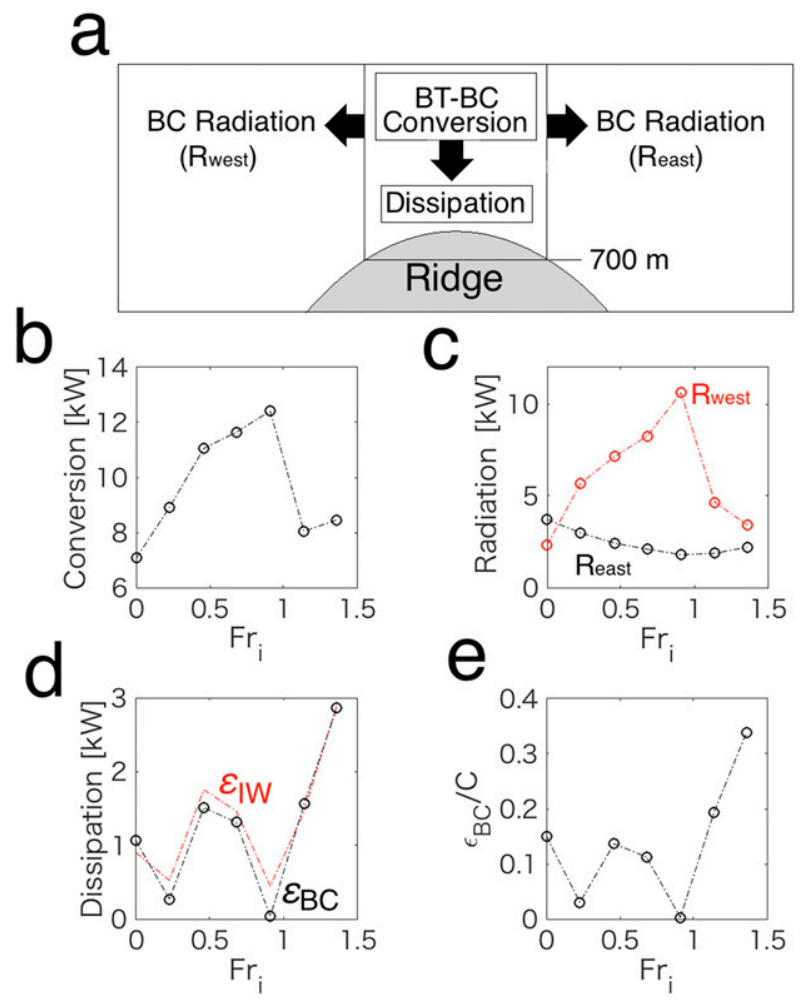

FIG. 8. (a) Schematic illustrating the energy budget analysis procedure. (b) BT-BC conversion rate over the ridge, (c) internal wave energy radiation from the ridge, $(\mathrm{d})$ total $\mathrm{BC}$ dissipation $\left(\varepsilon_{\mathrm{BC}}\right.$; black dash-dot line) and $\mathrm{BC}$ dissipation explained by internal waves ( $\varepsilon_{\mathrm{BC}}$; red dash dot line) over the ridge, and (e) ratio between the $\mathrm{BC}$ dissipation and $\mathrm{BT}-\mathrm{BC}$ conversion.

The BT-BC conversion increases as $\mathrm{Fr}_{i}$ increases under subcritical conditions and drops once $\mathrm{Fr}_{i}$ reaches the critical value $\left(\mathrm{Fr}_{i}=1\right.$, Fig. $\left.8 \mathrm{~b}\right)$. The Kuroshio has a potential to enhance the $\mathrm{BC}$ energy (internal wave) generation by a factor of 1.75 near the critical point (Run5). On the other hand, the fast Kuroshio under the supercritical conditions sharply reduces BC energy generation. The $\mathrm{BC}$ radiation on the west side of the ridge increases with $\mathrm{Fr}_{i}$ for subcritical cases and decreases for the supercritical cases demonstrating a trend similar to that for the BT-BC conversion. The westward $\mathrm{BC}$ radiation for the near-critical case (Run5) is 4.2 times greater than that for the case without the background current (Run1) (Fig. 8c). Meanwhile, on the east side of the ridge, the $\mathrm{BC}$ radiation slightly decreases (increases) with increasing $\mathrm{Fr}_{i}$ under sub- (super) critical conditions (Fig. 8c). The minimum eastward $\mathrm{BC}$ radiation for the near-critical case (Run5) is roughly half of the magnitude for the case without the background flow (Run1). As described above, the upstream (westward) $\mathrm{BC}$ energy flux (BC radiation) is remarkably enhanced by the background current under subcritical conditions, at which the upstream BC energy flux is approximately 6 times larger than that on the east side determined for the near-critical case. The $\mathrm{BC}$ dissipation does not exhibit an apparent relation to $\mathrm{Fr}_{i}$ under subcritical conditions; however, its value clearly increases with increasing $\mathrm{Fr}_{i}$ under supercritical conditions (Fig. 8d). Roughly $0.3 \%$ (34\%) of the total BC energy generated in Run5 is dissipated over the ridge at $\mathrm{Fr}_{i}=0.91$ (Run7 with $\mathrm{Fr}_{i}=1.36$ ) (Fig. 8e). This suggests that a large amount of the generated $\mathrm{BC}$ (or internal tidal) energy is radiated (dissipated) from the ridge (over the ridge) by the Kuroshio under the near- (super) critical conditions. Figure $8 \mathrm{~d}$ compares the $\mathrm{BC}$ dissipation estimated by the total $\mathrm{BC}$ energy flux $\left(\varepsilon_{\mathrm{BC}}\right)$ and that estimated only by the internal wave energy flux $\left(\varepsilon_{\mathrm{IW}}=\nabla_{H} \cdot \overline{F_{\mathrm{IW}}}-\bar{C}\right)$. The difference between $\varepsilon_{\mathrm{BC}}$ and $\varepsilon_{\mathrm{IW}}\left(\varepsilon_{\mathrm{BC}}-\varepsilon_{\mathrm{IW}}\right)$ ranges between -0.41 and $0.16 \mathrm{~kW}$. The $\mathrm{BC}$ kinetic energy term reduces $\varepsilon_{\mathrm{BC}}$ by a factor of approximately 10 . Thus, although the contribution of $\mathrm{KE}$ to the $\mathrm{BC}$ flux is much smaller than internal tides, the $\mathrm{BC}$ kinetic energy has to be considered when computing the tidal energy budget associated with the interaction between the background flows and tides.

\section{f. High-frequency internal waves}

High-frequency internal waves are generated in our numerical simulations. Figures $9 b-f$ shows the temporal evolution of the bandpass filtered vertical displacements of the main pycnocline $\left(\sigma_{T}=24.2\right)$ for Run5 in the frequencies of $\mathrm{M}_{2}-4 \mathrm{M}_{2}\left(f_{1}-f_{4}\right)$ and higher than $5 \mathrm{M}_{2}\left(f_{5}\right)$. The filter band range $f_{i}$ ( $i$ denotes the number of the harmonics) is $1.5 \times 10^{-5}<f_{1}<3.0 \times$ $10^{-5}<f_{2}<5.4 \times 10^{-5}<f_{3}<7.7 \times 10^{-5}<f_{4}<9.9 \times$ $10^{-5}<f_{5}<\infty \mathrm{s}^{-1}$. The internal wave phase speed along the pycnocline appears to be slower on the west side than that on the east side, which cannot be simply explained by the sum of the first mode internal wave speed $c_{i}$ and the background flow speed $U_{\mathrm{BK}}$, because the background flow is not uniform vertically. The black dash-dot lines $\left(C_{1}-C_{4}\right)$ in Fig. 9b represent the phase speeds of the first four vertical internal wave modes with the $\mathrm{M}_{2}$ tidal frequency estimated using normal mode analysis, whose magnitudes are equal to $2.6,1.3,0.9$, and $0.7 \mathrm{~m} \mathrm{~s}^{-1}$, respectively. The calculated phase speed fits the slope of the fourth vertical internal wave $\left(C_{4}\right)$ on the west side of the ridge (Fig. 9b). On the same side, the velocity distribution represents a multivertical mode structure (Fig. 9g), which implies that high vertical mode internal waves explain the displacements of the isotherm depth. The multivertical modal structure and associated slow internal wave phase speed also appear in the case without background flows (Run1, Figs. 10a-c). The internal wave phase speed is almost the same for Run1 and 


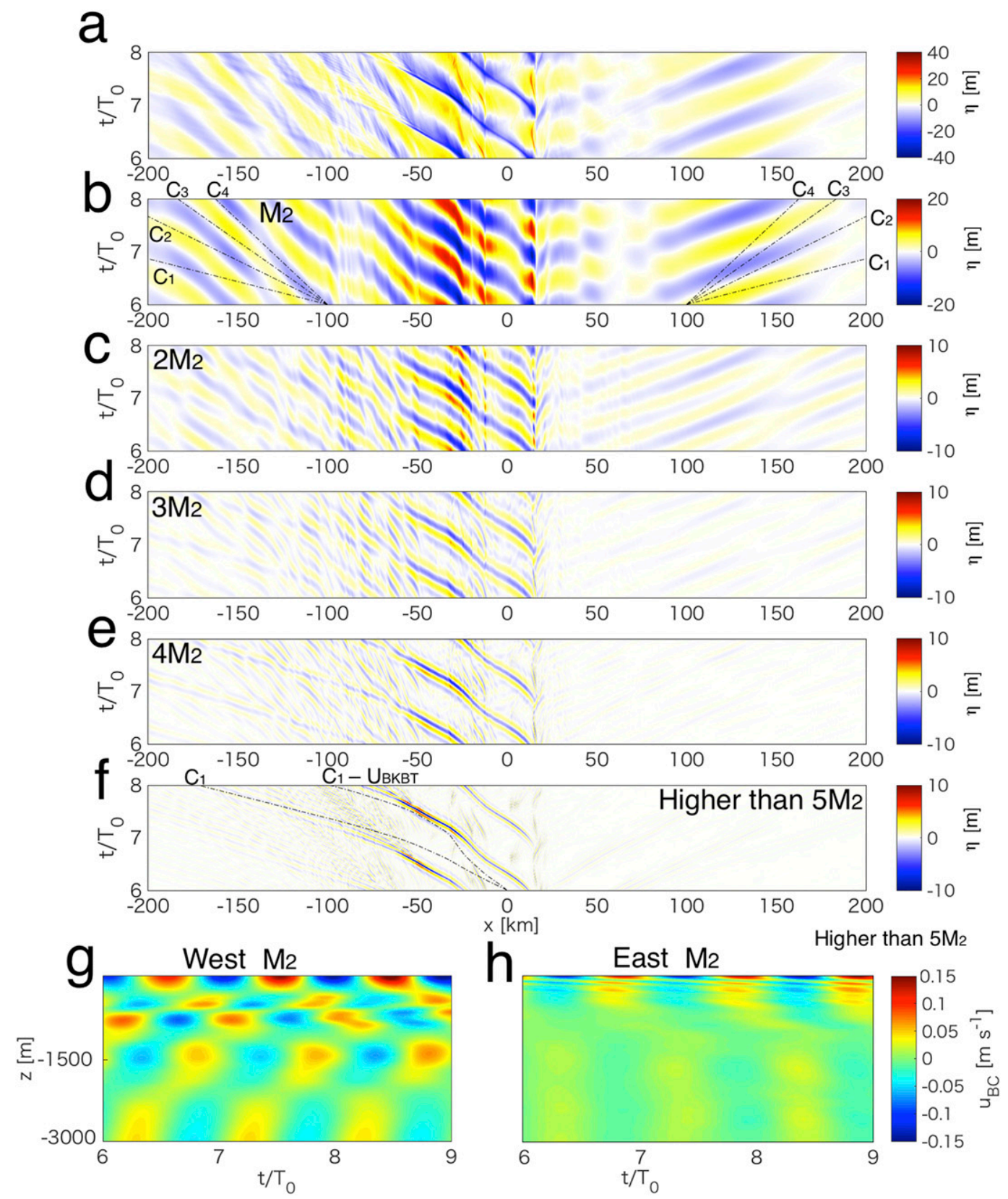

FIG. 9. (a)-(f) Vertical isopycnal displacements $\left(\sigma_{T}=24.2\right)$ and $(\mathrm{g}),(\mathrm{h}) \mathrm{BC}$ velocities in the frequency band of $\mathrm{M}_{2}$ on the (g) west (P1) and (h) east (P5) sides of the ridge for Run5 $\left(U_{\mathrm{BK}}=1.0 \mathrm{~m}, a=0.5\right)$. The bandpass filtered isopycnal displacements with frequencies (b) $\mathrm{M}_{2}$, (c) $2 \mathrm{M}_{2}$, (d) $3 \mathrm{M}_{2}$, (e) $4 \mathrm{M}_{2}$, and (f) higher than $5 \mathrm{M}_{2}$. The black dash-dot lines in (b) indicate the internal wave speed at a depth of $3000 \mathrm{~m}$, and subscripts $1-4$ denote the vertical mode numbers. The wave phase speed slope in (f), the black dashed lines, shows the first mode wave speed considering the bathymetry $\left(C_{1}\right)$, and the bathymetry and barotropic background flow $\left(C_{1}-U_{\mathrm{BKBT}}\right)$.

Run5 far away from the ridge $(x<-100 \mathrm{~km}$ and $x>$ $100 \mathrm{~km})$. BC horizontal velocities for the first four vertical modes estimated from the initial stratification are plotted in Figs. 10d-g. The BC velocity structure on the west side of the ridge can be roughly explained by the third or fourth mode. The second mode explains the BC velocity on the east side. Thus, the slow wave phase speed observed for the vertical isopycnal displacements can be explained by the presence of multivertical internal tides and the wave phase speed is not significantly influenced by the background flows far away from the top of the ridge. Previous observations and models 

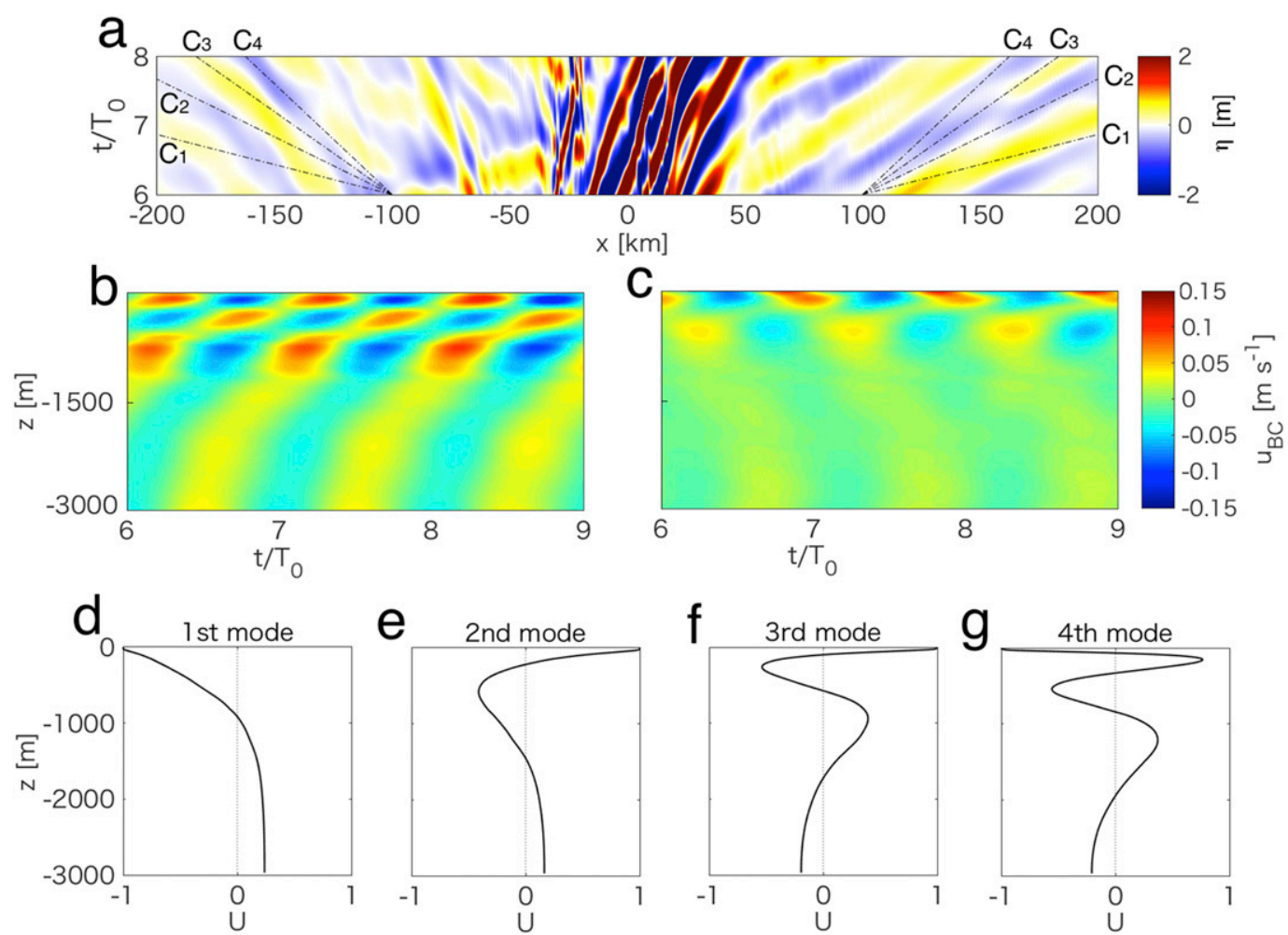

FIG. 10. (a) Vertical isopycnal displacements $\left(\sigma_{T}=24.2\right)$, (b),(c) BC velocities in the frequency band of $\mathrm{M}_{2}$ on the (b) west (P1) and (c) east (P5) sides of the ridge for Run1 $\left(U_{\mathrm{BK}}=0 \mathrm{~m}, a=0.5\right)$, and (d) $-(\mathrm{g})$ normalized $\mathrm{BC}$ horizontal velocities for first four vertical modes.

showed that the rough topography results in high-mode internal tides radiated from ridges (St. Laurent and Nash 2004; Zilberman et al. 2009; Vic et al. 2019). St. Laurent and Nash (2004) and Vic et al. (2019) showed dominant internal wave energy in high internal wave mode over the Mid-Atlantic ridge. In our model case, the shallow and rough topography causes the dominant high mode internal tides radiating off-ridge, which results in the slow propagation speed of internal tides. The difference of the modal structure on the west and east sides is due to the difference in the topography.

The isopycnal displacements produced at higher frequency than $5 \mathrm{M}_{2}\left(f>9.9 \times 10^{-5}\right)$ show that internal solitary waves are released upstream (westward) from the eastern shallow peak of the ridge during every tidal cycle (Fig. 9f, $x \sim 10 \mathrm{~km}$ ). The amplitude of these waves increases as they propagate westward over the shallow area of $-60<x<10 \mathrm{~km}$. Such waves generate wave packets containing several smaller internal waves through a process known as "wave fission," which is a common feature of the internal solitary waves with relatively large amplitudes (Nash and Moum 2005). Two first mode internal wave speeds are plotted in Fig. 9f as the black dash dotted lines taking into account of 1 ) the bathymetry $\left(C_{1}\right)$ and 2$)$ both of the bathymetry and barotropic (depth averaged) background flow $\left(C_{1}-\right.$ $\left.U_{\text {BKBT }}\right)$. The BT background flow speeds are 0.09 and $0.72 \mathrm{~m} \mathrm{~s}^{-1}$ at the depth of $3000 \mathrm{~m}$ and at the shallowest summit, respectively. The BT background flow is roughly 30 times slower than the internal wave speed far from the ridge $\left(C_{1}=2.57 \mathrm{~m} \mathrm{~s}^{-1}\right)$, meanwhile, it reaches $66 \%$ of the wave speed over the ridge $\left(C_{1}=\right.$ $\left.1.09 \mathrm{~m} \mathrm{~s}^{-1}\right)$. Although the two wave speeds do not completely match to the solitary wave speed appearing the isotherm displacements, the slope of $C_{1}-$ $U_{\mathrm{BKBT}}$ seems to be a better approximation than $C_{1}$. Therefore, the phase speed of the internal solitary waves is modulated by the background flow and can be roughly explained by the first mode internal wave speed taking into account of the BT background flow.

The time series data obtained at three different locations P2-4 with depths of 1500,1000 , and $500 \mathrm{~m}$ (see Fig. 2a) illustrates the growth of the internal solitary waves, which consists of the following steps (Fig. 11). 1) Single wave packets are formed during each tidal cycle at locations with depths of 500 and $1000 \mathrm{~m}$ and increasing wave amplitude as they propagate away from the ridge. 2) The internal solitary waves with large amplitudes are separated into several wave packets (wave fission) in the area deeper than $1500 \mathrm{~m}$. The internal solitary waves 

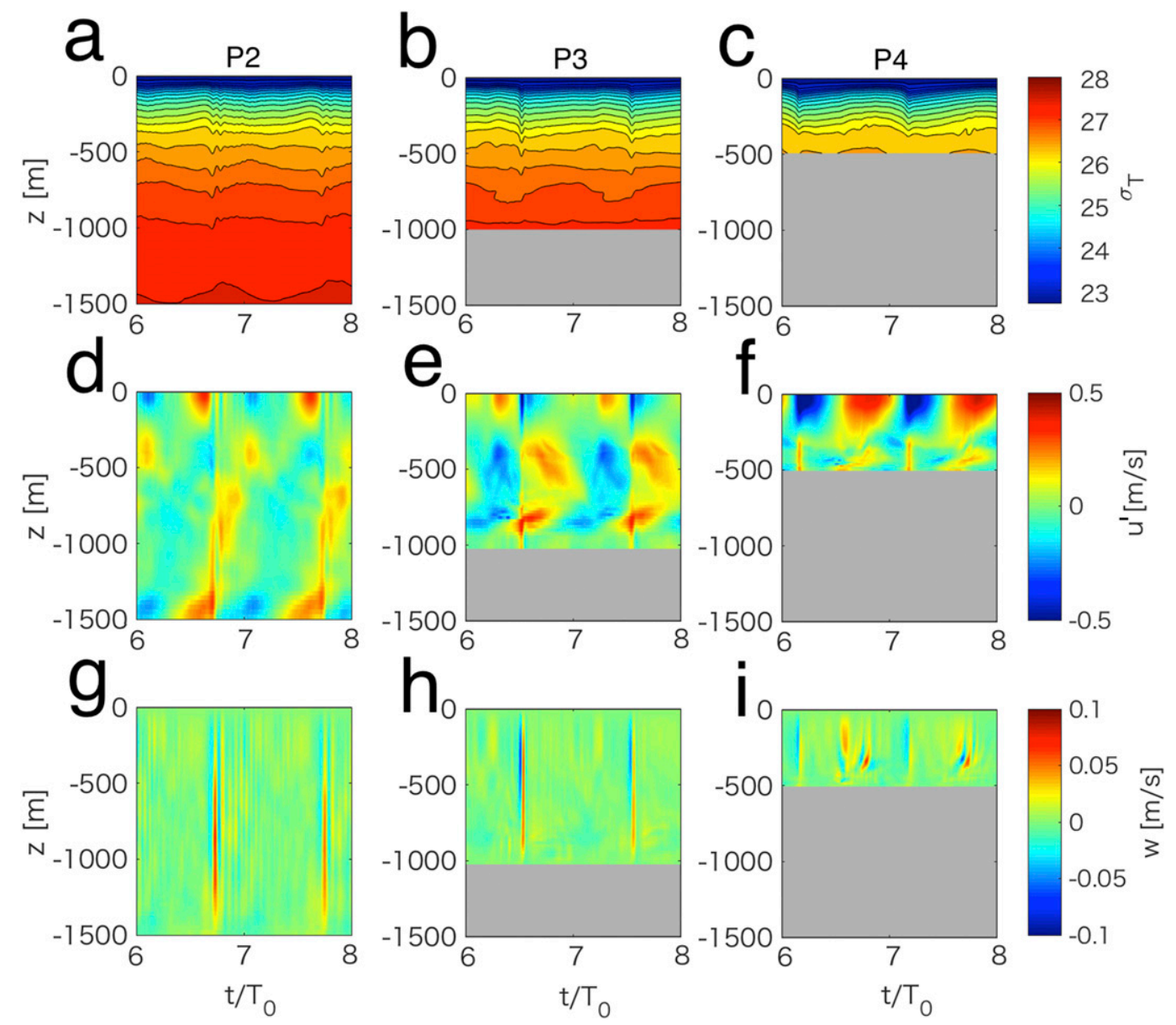

FIG. 11. (a)-(c) Densities, (d)-(f) horizontal perturbation velocities, and (g)-(i) vertical velocities obtained at locations (left) P2, (center) P3, and (right) P4 on the west side of the ridge during Run5 ( $\left.U_{\mathrm{BK}}=1.0 \mathrm{~m}, a=0.5\right)$.

produce strong vertical currents reaching a speed of $0.1 \mathrm{~m} \mathrm{~s}^{-1}$ at depths greater than $1000 \mathrm{~m}$.

The amplitude of high-frequency internal waves is relatively small on the east side of the ridge (Fig. 9f). The wave phase speed along the main isopycnal line is close to the speed of the second mode on the east side (Figs. 9b,f). The horizontal current distribution consists of a thin $\mathrm{BC}$ modal structure confined in the surface layer, which is significantly different from that on the west side. This structure may result from the fan-like stretched current distribution due to the multiple internal wave mode structure and their phases modulated by the vertical shear caused by the Kuroshio (see Fig. 5).

The high-frequency internal wave energy flux $\left(F_{\text {IWhigh }}\right)$ at frequencies higher than $2 \mathrm{M}_{2}\left(f>3.0 \times 10^{-5}\right)$ is computed via Eq. (7). Figures $12 \mathrm{a}$ and $12 \mathrm{~b}$ compare the values of $F_{\mathrm{IW}}$ and $F_{\mathrm{IWhigh}}$ for Run5. The internal wave energy flux at the frequency of $\mathrm{M}_{2}$ corresponds to the difference between $F_{\mathrm{IW}}$ and $F_{\mathrm{IWhigh}}\left(F_{\mathrm{IW}}-F_{\mathrm{IWhigh}}\right)$. The maximum magnitude of $F_{\text {IWhigh }}$ reaches $3.1 \mathrm{~kW} \mathrm{~m}^{-1}$ on the west side of the ridge (Fig. 12a, $x \sim-50 \mathrm{~km}$ ). The contribution of the high-frequency internal wave energy flux to the total flux ranges from $10 \%$ to $40 \%$ on the west side, which is consistent with the value shown by Masunaga et al. (2018), indicating that $14 \%$ of the total internal wave energy flux can be explained by the existence of higher harmonic internal tides over the Izu-Ogasawara Ridge. Meanwhile, similar to the isopycnal displacements (Fig. 9), the high-frequency internal wave energy flux is much lower on the east side than on the west side. The maximum eastward high-frequency internal wave flux is below $6.2 \times 10^{-2} \mathrm{~kW} \mathrm{~m}$, which is 50 times smaller than that on the west side.

Figure 12e compares the radiation of the high-frequency internal waves at the side boundaries of the analysis area (near the ridge summit with a depth of $700 \mathrm{~m}$ as schematically illustrated in Fig. 8a) detected in Run1-Run7. The westward radiation peaks near the critical $\mathrm{Fr}_{i}$ value, which is consistent with the total $\mathrm{BC}$ radiation (Fig. 8c). The contribution of high-frequency waves to the total 

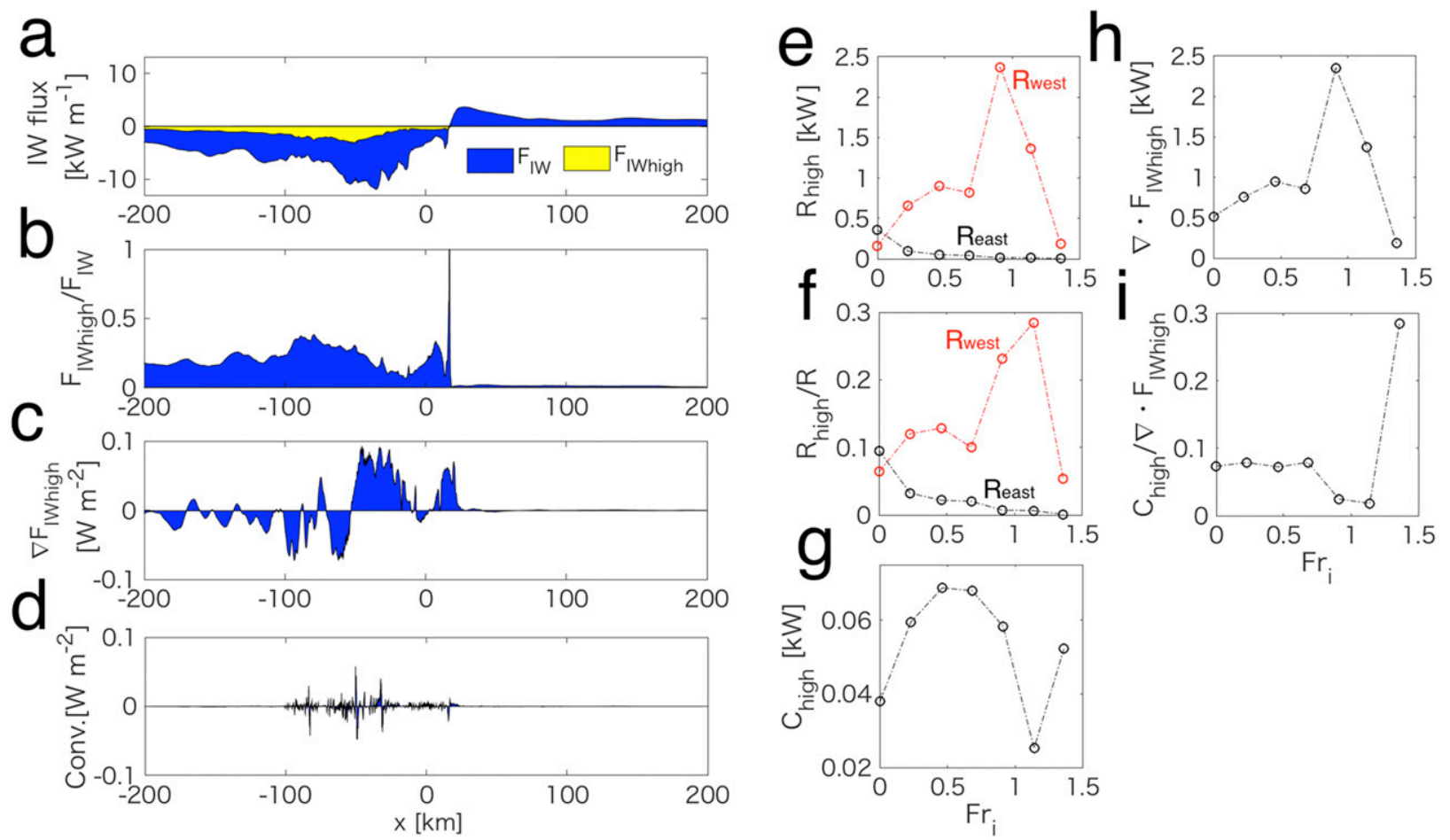

FIG. 12. (a) Total (blue) and high-frequency (yellow) internal wave energy fluxes, (b) contribution of the high-frequency internal wave flux to the total internal wave energy flux, (c) divergence of the high-frequency internal wave energy flux (d) high-frequency BT-BC conversion rate for Run5 ( $\left.U_{\mathrm{BK}}=1.0 \mathrm{~m}, a=0.5\right)$, (e) high-frequency internal wave radiation on the west (red) and east (black) sides of the ridge, and (f) contribution of the high-frequency internal wave radiation to the total radiation, area-integrated and time averaged ( $\mathrm{g}$ ) highfrequency BT-BC conversion and (h) the divergence of high-frequency internal waves, and (i) ratio between the high-frequency conversion and internal wave divergence as a function of the internal Froude number.

internal wave energy flux exceeds $20 \%$ for Run5 and Run6 (at $\mathrm{Fr}_{i}=0.91$ and 1.14, respectively, Fig. 12f). It is well known that large internal Froude numbers result in the formation of nonlinear high-frequency internal waves from the internal tides with lower frequencies through a hydraulic jump (Farmer and Armi 1999; Masunaga et al. 2017b). The large contributions of highfrequency waves observed near the critical conditions likely result from the enhancement of wave's nonlinearity due to the background current. On the other hand, the eastward high-frequency wave flux decreases as $\mathrm{Fr}_{i}$ increases (Fig. 12f). Nevertheless, the contribution of high-frequency internal waves observed for Run7 is less than $0.1 \%\left(\mathrm{Fr}_{i}=1.36\right)$, which indicates that these waves barely propagate on the downstream side at $\mathrm{Fr}_{i}>1$.

The generation of high-frequency internal wave can result from the nonlinear steepening of $\mathrm{M}_{2}$ internal tides or directly from BT tides (high-frequency BT-BC conversion $C_{\text {high }}$ ), and the generation can be roughly measured by the positive part of the divergence of highfrequency internal wave flux $\left(\nabla_{H} \cdot \overline{F_{\text {IWhigh }}}\right)$. The spatial distribution of the divergence of high-frequency internal wave energy flux shows enhanced generation of high-frequency internal tides over the shallow ridge (Fig. 12c, $-50<x<20$ ). Noisy positive and negative values of the high-frequency conversion next to each other indicates that the high-frequency BT-BC or BC-BT energy conversion occurs at a small scale on an order of $1-10 \mathrm{~km}$ (Fig. 12d). Negative values of the conversion indicate dissipation of high-frequency internal tides, or energy transfer to lower frequency internal tides or BT tides. The area integrated $\overline{C_{\text {high }}}$ and $\nabla_{H} \cdot \overline{F_{\text {IWhigh }}}$ over the analysis area for Run1-7 are plotted in Figs. $12 \mathrm{~g}$ and $12 \mathrm{~h}$. The range of the areaintegrated $\overline{C_{\text {high }}}$ is $0.02-0.07 \mathrm{~kW}$, which is less than $1 \%$ of the total BT-BC conversion. The area-integrated $\nabla_{H}$. $\overline{F_{\text {IWhigh }}}$ is more than 10 times higher than the highfrequency BT-BC conversion for Run1-6, which implies that the generation of high-frequency internal waves is dominated by the conversion from $\mathrm{M}_{2}$ internal tides. The conversion from $\mathrm{M}_{2}$ internal tides to high-frequency internal waves is probably due to nonlinear steepening of $\mathrm{M}_{2}$ internal tides caused by the Kuroshio-tides interaction. For the case with the strongest Kuroshio ( $R u n 7, \mathrm{Fr}_{i}=1.36$ ), the contribution of the high-frequency 
BT-BC conversion becomes larger than other cases and it reaches $28 \%$ of the divergence of the high-frequency internal wave flux (Fig. 12i).

\section{g. Deep ocean mixing}

It is well known that internal tides significantly contribute to mixing in the ocean (e.g., Munk and Wunsch 1998). A recent study of Vic et al. (2019) reported that high-mode internal tides significantly contribute to local mixing. In addition to local mixing near internal wave generation sites, the internal tides/waves radiate offshore and presumably contribute to deep ocean mixing far from their generation sites, known as far-field internal tide dissipation (MacKinnon et al. 2017). Internal tides radiate away from generation sites through lowmode internal waves, which contributes to roughly $20 \%-80 \%$ of the total internal tide dissipation in the ocean (MacKinnon et al. 2017). The vertical eddy diffusivity estimated using the Mellor-Yamada level 2.5 turbulent closure model (Mellor and Yamada 1982) is used to evaluate the mixing intensity in the present study. The time-averaged vertical eddy diffusivities for Run1, Run5 $5_{\text {w/oTide }}$, and Run5 are plotted in Fig. 13. The no-current case (Run1) exhibits strong diffusivity around the internal wave ray paths over the ridge (Fig. 13a) with a nearly symmetric pattern and equal magnitudes on both the west and east sides of the ridge. For Run $5_{w / o t i d e}$, the vertical shear due to the Kuroshio produces a remarkable increase in diffusivity in the subsurface layer (Fig. 13b), and the eddy diffusivity reaches a magnitude of $1 \times 10^{-4} \mathrm{~m}^{2} \mathrm{~s}^{-1}$. In a previous study, an eddy diffusivity of $O\left(10^{-4}-10^{-3}\right) \mathrm{m}^{2} \mathrm{~s}^{-1}$ was observed along the Kuroshio axis (Nagai et al. 2012), which was consistent with the results of our simulations. The Kuroshio produces an asymmetric mixing structure on the west and east sides of the ridge, in which the vertical mixing is enhanced on its east side at $z<-1000 \mathrm{~m}$ (Fig. 13b). Such a structure is commonly formed over a sill and has been frequently observed in the atmosphere and ocean (Farmer and Denton 1985; Edwards et al. 2004; Liu et al. 2016). The enhanced vertical mixing on the east (downstream) side of the ridge observed in our simulations may reflect effects of the background flow and an internal hydraulic jump. In the run that takes into account both the background flow and tides (Run5, Fig. 13c), the eddy diffusivity on the east side is almost identical to that in Run $5_{\mathrm{w} / \mathrm{oTide}}$; however, its magnitude calculated for the deep area $(z<-1000 \mathrm{~m})$ on the west side exceeds the values in Run 1 and Run $5_{w / o T i d e}$.

To further investigate the deep ocean mixing due to the interaction of the Kuroshio with internal tides, the time and spatially averaged vertical eddy diffusivities in bottom cells computed at depths ranging between 1500
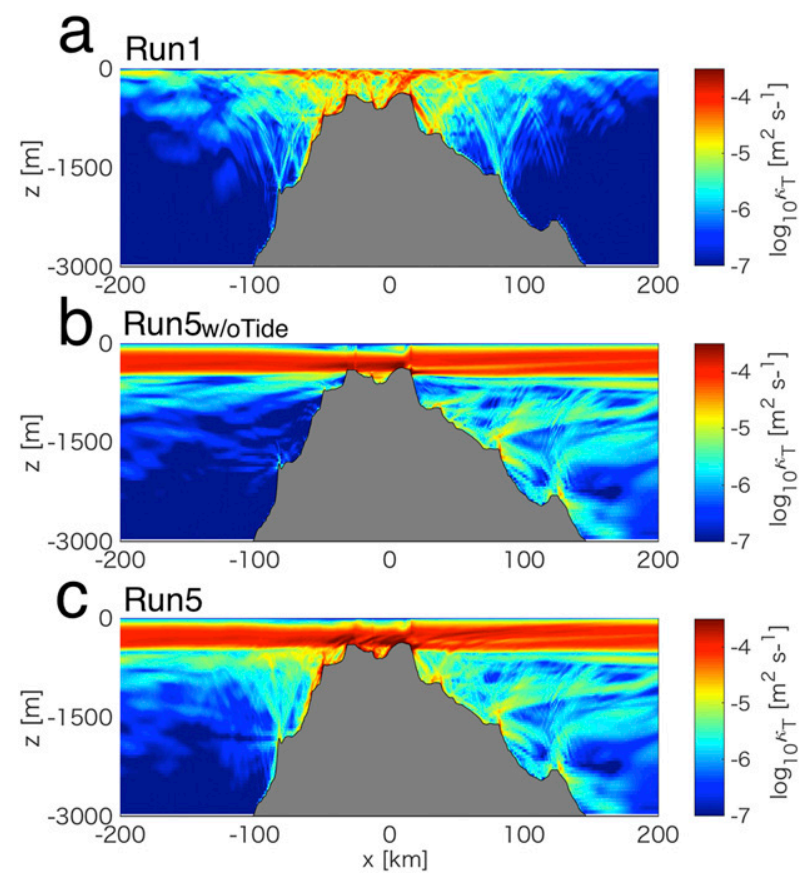

FIG. 13. Time-averaged vertical eddy diffusivity estimated using the Mellor-Yamada turbulent closure model for (a) Run1, (b) Run5 $5_{\text {w/oTide }}$, and (c) Run5.

and $2500 \mathrm{~m}$ are compared for all model cases. The range of $1500-2500 \mathrm{~m}$ is selected, because the near surface layer (depth $<1500 \mathrm{~m}$ ) is directly influenced by the background flows and the deep layer (depth $>2500 \mathrm{~m}$ ) does not show significant differences of the eddy diffusivity between the three cases. Figures $14 \mathrm{a}$ and $14 \mathrm{~b}$ show the averaged eddy diffusivities for the west and east sides of the ridge. The eddy diffusivity on the west side exhibits a peak of $7.5 \times 10^{-6} \mathrm{~m}^{2} \mathrm{~s}^{-1}$ at $\mathrm{Fr}_{i} \sim 1$ and tidal forcing, which is much larger than the sum of the eddy diffusivities obtained in Run1 (with tidal forcing and $\left.\mathrm{Fr}_{i}=0\right)$ and Run $2_{\mathrm{w} / \mathrm{oTide}}-\mathrm{Run} 7_{\mathrm{w} / \mathrm{oTide}}$. In addition, the bottom eddy diffusivity is almost proportional to the upstream internal wave energy flux under subcritical conditions $\left(\mathrm{Fr}_{i}<1\right.$; see Fig. $\left.14 \mathrm{c}\right)$. In the turbulent closure scheme of the present model, the shear production term $(\propto d u / d z)^{2}$ typically transfers energy from the mean flow into the turbulent kinetic energy (TKE), while the buoyancy flux term $\left(\propto N^{2}\right)$ reduces the TKE. The differences in the vertical eddy diffusivity between the model cases may largely be caused by the differences in the vertical shear because the background stratification for all cases is the same. The interaction of the Kuroshio and tides enhances the $\mathrm{BC}$ velocity in deep regions (cf. Fig. 9g with Fig. 10b). Thus, near-bottom currents enhanced by internal tides due to the interaction result in elevated mixing in the deep bottom boundary layer. In turn, the eddy diffusivity on the east side simply 

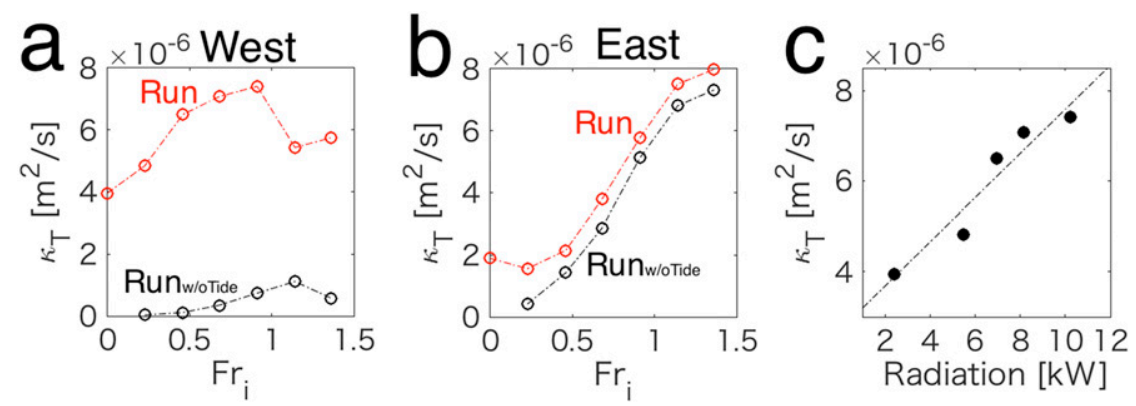

FIG. 14. Time and spatially averaged eddy diffusivities at the bottom boundary layer and depths ranging from 1500 to $2500 \mathrm{~m}$ on the (a) west and (b) east sides of the ridge estimated for Run1-Run7 (red) and Run2 ${ }_{\text {w/oTide }}-$ Run $_{\text {w/oTide }}$ (black). (c) Bottom eddy diffusivity on the west side plotted as a function of the westward internal wave flux radiation at $\mathrm{Fr}_{i}<1$.

increases as $\mathrm{Fr}_{i}$ increases (Fig. 14b). The contribution of tidal forcing to the total bottom eddy diffusivity is roughly $1 \times 10^{-6} \mathrm{~m}^{2} \mathrm{~s}^{-1}$ (see the differences in the eddy diffusivity between Run2-Run7 and Run2 $2_{\text {w/oTide }}-$ Run $\left.7_{\text {w/oTide }}\right)$.

The vertical eddy diffusivity estimated by our simulations suggests that the enhancement by the interaction of the Kuroshio and tides is quite small compared with that in energetic oceans directly influenced by geostrophic flows, tides and internal waves, reaching an order of $10^{-4}-10^{-2} \mathrm{~m}^{2} \mathrm{~s}^{-1}$ (e.g., Masunaga et al. 2015; Nagai et al. 2017). By contrast to such energetic oceans, the vertical eddy diffusivity is low in calm deep oceans, an order of $10^{-6} \mathrm{~m}^{2} \mathrm{~s}^{-1}$ (Ferron et al. 2014; Shang et al. 2017). The intensified vertical shear in the strong internal tides generated by the Kuroshio-tides interaction is able to contribute to the deep ocean mixing in the upstream region of the Kuroshio.

\section{Conclusions}

In this study, the generation of strong internal tides influenced by the interaction of the Kuroshio and tides over a shallow ridge is described using the fully nonlinear nonhydrostatic hydrodynamic SUNTANS model. The results of several runs conducted at different internal Froude numbers show that the upstream propagating internal tides enhanced by the Kuroshio with the internal wave energy flux reaching a magnitude of $12.0 \mathrm{~kW} \mathrm{~m}^{-1}$ near the critical condition $\left(\mathrm{Fr}_{i} \sim 1\right)$ due to the interaction of the Kuroshio and tides. The strong upstream propagating internal tides are accompanied by high-frequency and solitary internal waves, which likely amplify deep ocean mixing in the upstream region relative to the ridge. In contrast, the downstream internal tides are suppressed by the Kuroshio and tides interaction.

Results shown in this study support the strong upstream internal tide energy flux from the Izu-Ogasawara Ridge found by Masunaga et al. (2018) (Fig. 1d). The first mode internal wave phase speed around the IzuOgasawara Ridge is plotted in Fig. 15a, in which the results from Masunaga et al. (2018) were used for the phase speed estimation. The phase speed of internal waves ranges between 1 and $2 \mathrm{~m} \mathrm{~s}^{-1}$ (Fig. 15a), except for
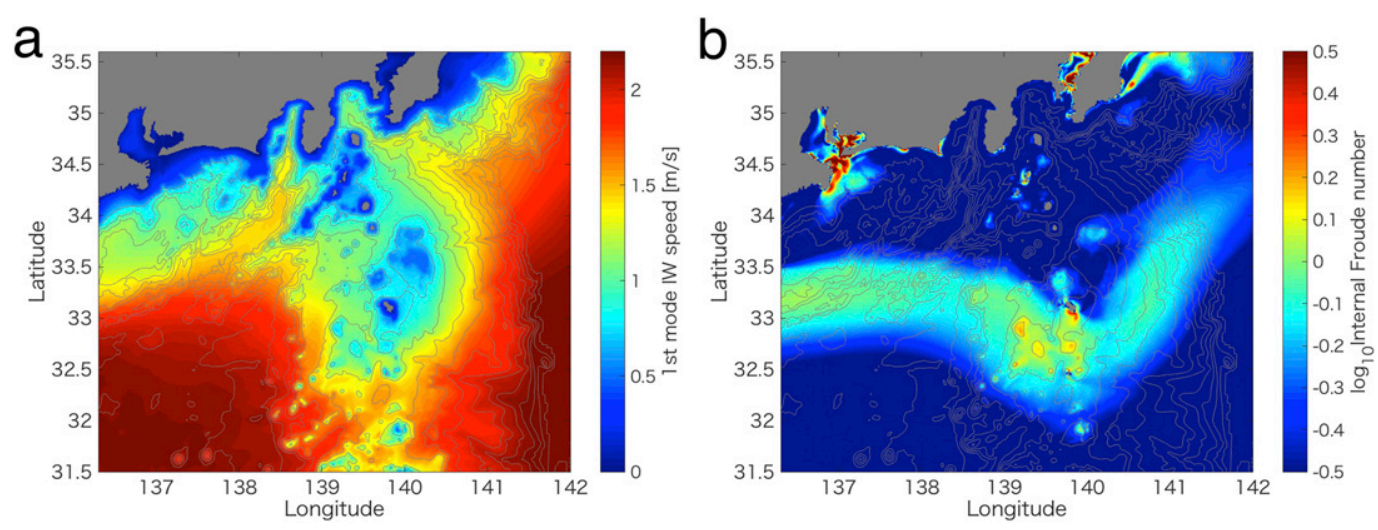

FIG. 15. (a) First vertical mode of the internal wave phase speed and (b) internal Froude number plotted for August 2014 using the numerical simulation data provided by Masunaga et al. (2018). The gray contours denote the isobath intervals of $500 \mathrm{~m}$. 
shallow coastal regions, and the current speed of the Kuroshio also ranges roughly between 1 and $2 \mathrm{~m} \mathrm{~s}^{-1}$ (Fig. 1a). This matching of the internal wave speed and the Kuroshio flow speed results in $\mathrm{Fr}_{i} \sim 1$ along the Kuroshio path (Fig. 15b). The combination of the critical $\mathrm{Fr}_{i}$ condition and strong tidal flows over the IzuOgasawara Ridge causes strong internal tide energy flux upstream of the Kuroshio shown in Fig. 1d. Furthermore, the strong internal tides formed by the interaction of the Kuroshio and tides may promote mixing and transport along the Kuroshio flow.

The majority of previous studies have separately focused on geostrophic flows (such as the Kuroshio and Gulf Stream) and internal tides. However, both phenomena coexist in world's oceans, for example, Tokara Strait (Nagai et al. 2017), Luzon Strait (Da Silva et al. 2015), and Straits of Florida (Davis et al. 2008). Strong internal tides can be generated by the interaction of the background flow and tides in any areas other than the Izu-Ogasawara Ridge at critical $\mathrm{Fr}_{i}$ values. The internal tides transport heat and mass across the oceans and are known as an important contributor to maintaining the global ocean circulations and ecosystems (e.g., Walsh 1991; Sharples et al. 2009; Masunaga et al. 2017a). Hence, the strong internal tides generated by the background flow and tides are anticipated to contribute to circulations and ecosystems in the ocean.

Acknowledgments. This study was supported by JST-CREST (grant No. JPMJCR12A6). E. Masunaga and Y. Uchiyama acknowledge the JSPS Grant-in-Aid for Scientific Research (No. 18H03798).

\section{APPENDIX}

\section{Validation Test for the Averaging Time Scale}

To validate the averaging time scale used for computing the internal wave energy flux and energy budget, the internal wave energy flux is compared with time averages over two, three, and four $\mathrm{M}_{2}$ cycles $\left(t / T_{0}=6-8\right.$, 6-9 and 6-10) for Run1. Time series of the internal wave energy flux on the west and east sides of the ridge (depth of $700 \mathrm{~m}$ ) and the time-averaged internal wave flux for the three periods are shown in Fig. A1. The time series data represent similar patterns of the internal wave energy flux repeated in each tidal phase without any substantial low-frequency biases. The estimated timeaveraged internal wave energy flux also shows a consistency for the three averaging periods. The time-averaged internal wave flux on the west (east) side of the ridge is $-2.41(3.79),-2.49(3.82)$, and $-2.53(3.70) \mathrm{kW} \mathrm{m}^{-2}$

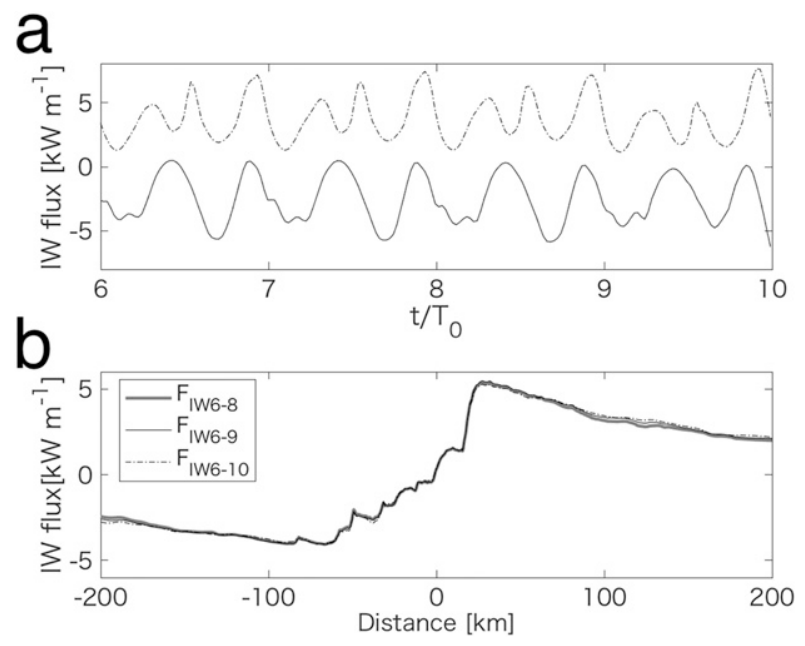

FIG. A1. (a) Internal wave flux as a function of $t / T_{0}$ on the west (solid line) and east (dash-dot line) sides, and (b) time-averaged internal wave flux computed for periods of 6-8 (thick gray line), 6-9 (thin black line), and 6-10 (black dash-dot line) $\mathrm{M}_{2}$ cycles.

for the period of $t / T_{0}=6-8,6-9$, and 6-10, respectively. Therefore, we assume that two tidal cycles are sufficient to obtain reasonable averaged quantities.

\section{REFERENCES}

Alford, M. H., and Coauthors, 2015: The formation and fate of internal waves in the South China Sea. Nature, 521, 65-69, https://doi.org/10.1038/nature14399.

Arthur, R. S., and O. B. Fringer, 2016: Transport by breaking internal waves on slopes. J. Fluid Mech., 789, 93-126, https:// doi.org/10.1017/jfm.2015.723.

Bourgault, D., M. Morsilli, C. Richards, U. Neumeier, and D. E. Kelley, 2014: Sediment resuspension and nepheloid layers induced by long internal solitary waves shoaling orthogonally on uniform slopes. Cont. Shelf Res., 72, 21-33, https://doi.org/ 10.1016/j.csr.2013.10.019.

Cacchione, D. A., L. F. Pratson, and A. S. Ogston, 2002: The shaping of continental slopes by internal tides. Science, 296, 724-727, https://doi.org/10.1126/science.1069803.

Da Silva, J. C. B., M. C. Buijsman, and J. M. Magalhaes, 2015: Internal waves on the upstream side of a large sill of the Mascarene Ridge: A comprehensive view of their generation mechanisms and evolution. Deep-Sea Res. I, 99, 87-104, https://doi.org/10.1016/j.dsr.2015.01.002.

Davis, K.A., J. J. Leichter, J. L. Hench, and S. G. Monismith, 2008: Effects of western boundary current dynamics on the internal wave field of the Southeast Florida shelf. J. Geophys. Res., 113, C09010, https://doi.org/10.1029/2007JC004699.

Edwards, K. A., P. MacCready, J. N. Moum, G. Pawlak, J. M. Klymak, and A. Perlin, 2004: Form drag and mixing due to tidal flow past a sharp point. J. Phys. Oceanogr., 34, 1297-1312, https:// doi.org/10.1175/1520-0485(2004)034<1297:FDAMDT>2.0.CO;2.

Farmer, D. M., and R. A. Denton, 1985: Hydraulic control of flow over the sill in Observatory Inlet. J. Geophys. Res., 90, 9051-9068, https://doi.org/10.1029/JC090iC05p09051.

, and L. Armi, 1999: The generation and trapping of solitary waves over topography. Science, $\mathbf{2 8 3}, 188-190$, https://doi.org/ 10.1126/science.283.5399.188. 
Ferron, B., F. Kokoszka, H. Mercier, and P. Lherminier, 2014: Dissipation rate estimates from microstructure and finescale internal wave observations along the A25 Greenland-Portugal OVIDE line.J. Atmos. Oceanic Technol., 31, 2530-2543, https:// doi.org/10.1175/JTECH-D-14-00036.1.

Fringer, O. B., M. Gerritsen, and R. L. Street, 2006: An unstructured-grid, finite-volume, nonhydrostatic, parallel coastal ocean simulator. Ocean Modell., 14, 139-173, https://doi.org/ 10.1016/j.ocemod.2006.03.006.

Guo, C., and X. Chen, 2014: A review of internal solitary wave dynamics in the northern South China Sea. Prog. Oceanogr., 121, 7-23, https://doi.org/10.1016/j.pocean.2013.04.002.

Hasegawa, D., H. Yamazaki, T. Ishimaru, H. Nagashima, and Y. Koike, 2008: Apparent phytoplankton bloom due to island mass effect. J. Mar. Syst., 69, 238-246, https://doi.org/10.1016/ j.jmarsys.2006.04.019.

Kang, D., and O. Fringer, 2012: Energetics of barotropic and baroclinic tides in the Monterey Bay area. J. Phys. Oceanogr., 42, 272-290, https://doi.org/10.1175/JPO-D-11-039.1.

Lamb, K. G., and M. Dunphy, 2018: Internal wave generation by tidal flow over a two-dimensional ridge: Energy flux asymmetries induced by a steady surface trapped currents. J. Fluid Mech., 836, 192-221, https://doi.org/10.1017/jfm.2017.800.

Liu, Z., T. Ishihara, T. Tanaka, and X. He, 2016: LES study of turbulent flow fields over a smooth 3-D hill and a smooth 2-D ridge. J. Wind Eng. Ind. Aerodyn., 153, 1-12, https://doi.org/ 10.1016/j.jweia.2016.03.001.

MacKinnon, J. A., and Coauthors, 2017: Climate process team on internal wave-driven ocean mixing. Bull. Amer. Meteor. Soc., 98, 2429-2454, https://doi.org/10.1175/BAMS-D-16-0030.1.

Masunaga, E., H. Homma, H. Yamazaki, O. B. Fringer, T. Nagai, Y. Kitade, and A. Okayasu, 2015: Mixing and sediment resuspension associated with internal bores in a shallow bay. Cont. Shelf Res., 110, 85-99, https://doi.org/10.1016/j.csr.2015.09.022.

, R. S. Arthur, O. B. Fringer, and H. Yamazaki, 2017a: Sediment resuspension and generation of intermediate nephew layers by shoaling internal bores. J. Mar. Syst., 170, 31-41, https://doi.org/10.1016/j.jmarsys.2017.01.017.

_ O. B. Fringer, Y. Kitade, H. Yamzaki, and S. M. Gallager, 2017b: Dynamics and energetics of trapped diurnal internal Kelvin waves around a mid-latitude island. J. Phys. Oceanogr., 47, 2479-2498, https://doi.org/10.1175/JPO-D-16-0167.1.

_- Y. Uchiyama, Y. Suzue, and H. Yamazaki, 2018: Dynamics of internal tides over a shallow ridge investigated with a highresolution downscaling regional ocean model. Geophys. Res. Lett., 45, 3550-3558, https://doi.org/10.1002/2017GL076916.

Mei, C. C., 1992: The Applied Dynamics of Ocean Surface Waves. Advanced Series on Ocean Engineering, Vol. 1, World Scientific, $768 \mathrm{pp}$.

Mellor, G. L., and T. Yamada, 1982: Development of a turbulence closure model for geophysical fluid problems. Rev. Geophys., 20, 851-875, https://doi.org/10.1029/RG020i004p00851.

Merrifield, M. A., and P. E. Holloway, 2002: Model estimates of M2 internal tide energetics at the Hawaiian Ridge. J. Geophys. Res., 107, 3179, https://doi.org/10.1029/2001JC000996.

Millero, F. J., and A. Poisson, 1981: International one-atmosphere equation of state of seawater. Deep-Sea Res., 28A, 625-629, https://doi.org/10.1016/0198-0149(81)90122-9.
Munk, W., and C. Wunsch, 1998: Abyssal recipes II: Energetics of tidal and wind mixing. Deep-Sea Res. I, 45, 1977-2010, https:// doi.org/10.1016/S0967-0637(98)00070-3.

Nagai, T., A. Tandon, H. Yamazaki, M. J. Doubell, and S. Gallager, 2012: Direct observations of microscale turbulence and thermohaline structure in the Kuroshio Front. J. Geophys. Res. Oceans, 117, C08013, https://doi.org/10.1029/2011JC007228.

- D. Hasegawa, T. Tanaka, H. Nakamura, E. Tsutsumi, R. Inoue, and T. Yamashiro, 2017: First evidence of coherent bands of strong turbulent layers associated with highwavenumber internal-wave shear in the upstream Kuroshio. Sci. Rep., 7, 14555, https://doi.org/10.1038/s41598-017-15167-1.

Nash, J. D., and J. N. Moum, 2005: River plumes as a source of large-amplitude internal waves in the coastal ocean. Nature, 437, 400-403, https://doi.org/10.1038/nature03936.

Nikurashin, M., and R. Ferrari, 2010: Radiation and dissipation of internal waves generated by geostrophic motions impinging on small-scale topography: Theory. J. Phys. Oceanogr., 40, 1055-1074, https://doi.org/10.1175/2009JPO4199.1.

Richards, C., D. Bourgault, P. S. Galbraith, A. Hay, and D. E. Kelley, 2013: Measurements of shoaling internal waves and turbulence in an estuary. J. Geophys. Res. Oceans, 118, 273-286, https://doi.org/10.1029/2012JC008154.

Rudnick, D. L., and Coauthors, 2003: From tides to mixing along the Hawaiian Ridge. Science, 301, 355-357, https://doi.org/ 10.1126/science.1085837.

Shang, X., Y. Qi, G. Chen, C. Liang, R. G. Lueck, B. Prairie, and H. Li, 2017: An expendable microstructure profiler for deep ocean measurements. J. Atmos. Oceanic Technol., 34, 153-165, https://doi.org/10.1175/JTECH-D-16-0083.1.

Sharples, J., C. M. Moore, A. E. Hickman, P. M. Holligan, J. F. Tweddle, M. R. Palmer, and J. H. Simpson, 2009: Internal tidal mixing as a control on continental margin ecosystems. Geophys. Res. Lett., 36, L23603, https://doi.org/10.1029/ 2009GL040683.

St. Laurent, L. C., and J. D. Nash, 2004: An examination of the radiative and dissipative properties of deep ocean internal tides. Deep-Sea Res. II, 51, 3029-3042, https://doi.org/10.1016/ j.dsr2.2004.09.008.

Venayagamoorthy, S. K., and O. B. Fringer, 2006: Numerical simulations of the interaction of internal waves with a shelf break. Phys. Fluids, 18, 076603, https://doi.org/10.1063/ 1.2221863.

Vic, C., and Coauthors, 2019: Deep-ocean mixing driven by small-scale internal tides. Nat. Commun., 10, 2099, https:// doi.org/10.1038/s41467-019-10149-5.

Walsh, J. J., 1991: Importance of continental margins in the marine biogeochemical cycling of carbon and nitrogen. Nature, 350, 53-55, https://doi.org/10.1038/350053a0.

Zhang, Z., O. B. Fringer, and S. R. Ramp, 2011: Threedimensional, nonhydrostatic numerical simulation of nonlinear internal wave generation and propagation in the South China Sea. J. Geophys. Res., 116, C05022, https://doi.org/10.1029/ 2010JA016287.

Zilberman, N. V., J. M. Becker, M. A. Merrifield, and G. S. Carter, 2009: Model estimates of $M_{2}$ internal tide generation over Mid-Atlantic Ridge topography. J. Phys. Oceanogr., 39, 2635-2651, https://doi.org/10.1175/2008JPO4136.1. 